\title{
Comunidades de Relações Internacionais na América Latina: uma análise das tendências a partir do TRIP 2014
}

\author{
International Relations Communities in Latin \\ America: an analysis of trends from TRIP 2014
}

DOI: $10.21530 /$ ci.v12n1.2017.553

\author{
Rafael Duarte Villa ${ }^{1}$ \\ Arlene B. Tickner ${ }^{2}$ \\ Marília Carolina B. Souza ${ }^{3}$ \\ Yamile Carolina Cepeda Másmela ${ }^{4}$
}

\section{Resumo}

Este relatório tem por objetivo divulgar as principais tendências verificadas nos resultados do Projeto Teaching. Research \& Internacional Policy (TRIP), de 2014, entre as comunidades epistêmicas latino-americanas da Argentina, Brasil, Chile, Colômbia e México. Os resultados do relatório referem-se às preferências que estas comunidades apresentam quanto ao seu formato, opções metodológicas e epistemológicas; percepções quanto à dominação norte-americana da área e; por fim, suas impressões sobre política internacional.

Palavras-chave: TRIP, América Latina, Comunidades Epistêmicas, Tendências.

\begin{abstract}
This report aims to disclose the main trends observed in the results of the Project "Teaching. Research \& International Policy” (TRIP), of 2014, among the Latin American epistemic communities of Argentina, Brazil, Chile, Colombia and Mexico. The results of the report refer to the preferences of these communities regarding their format, methodological and epistemological options, perceptions regarding the North American domination of the field and, finally, their impressions on international politics.

Key-words: TRIP, Latin America, Epistemic Communities, Tendencies.

1 Professor Associado de Relações internacionais na Universidade de São Paulo (Brasil). E-mail: rafaelvi@usp.br

2 Professora titular do Departamento de Ciência Política da Universidad del Rosario (Colômbia). E-mail: arleneb.tickner@urosario.edu.co

3 Professora Doutora da Universidade Anhembi Morumbi (Brasil).E-mail: profa.marilia.csouza@gmail.com

4 Professora Assistente na Pontificia Universidade Javeriana (Colombia). E-mail: carocep@gmail.com

Artigo submetido em 24/09/2016 e aprovado em 31/01/2017.
\end{abstract}




\section{Introdução}

O presente relatório tem por objetivo divulgar para o meio acadêmico em geral as principais tendências verificadas nos resultados do projeto Teaching Research and International Policy (TRIP) de 2014 (MALINIAK et al.) para os países da América Latina: Argentina, Brasil, Chile, Colômbia e México. Os resultados se referem a percepções em torno da comunidade epistêmica latino-americana de Relações Internacionais, quanto ao seu formato, preferências metodológicas, epistemológicas, percepções quanto à dominação norte-americana da área e impressões sobre política internacional.

O projeto TRIP (MALINIAK et al.) está em curso desde 2004, é sediado pelo Institute for the Theory and Practice of International Relations da William \& Mary College e hoje contempla mais de 33 países. O TRIP busca, por meio de um survey enviado a acadêmicos e docentes de Relações Internacionais dos cinco continentes, o qual contempla uma série de questões, respondidas de forma voluntária, conhecer mais a fundo, a partir do olhar dos acadêmicos, as comunidades de relações internacionais e suas perspectivas globais. $\mathrm{O}$ objetivo é, sobretudo, encontrar relações entre o processo de ensino e o desenvolvimento de pesquisa e, por conseguinte, qual a possível influência que a comunidade epistêmica pode exercer sobre a política externa de seu país, e quais as percepções desta comunidade epistêmica sobre a política internacional. A última versão do TRIP foi aplicada em 2014 e a próxima será em 2017. Ainda em 2014, foram incluídos no survey 32 países, já com os cinco latino-americanos mencionados acima, os quais foram incluídos no survey ainda em 2011.

Este relatório, portanto, além de divulgar e comunicar as principais tendências para a comunidade epistêmica latino-americana de RI, possibilita refletir sobre uma possível identidade em ascensão, qual seja, em maior ou menor medida, dissonante da irradiada pelas comunidades anglo-saxônicas de relações internacionais, consideradas mainstream na disciplina de RI, bem como fornecer insumos de pesquisa à comunidade brasileira de Relações Internacionais, diante dos crescentes esforços de construir um arcabouço, tanto metodológico, quanto teórico, de reflexão sobre a área de Relações Internacionais no país e na região.

Reflexo disso foi a criação, no âmbito da Associação Brasileira de Relações Internacionais (ABRI), da sessão temática "Ensino e Pesquisa em Relações Internacionais", enquanto um espaço profícuo para debater e refletir sobre as conexões entre pesquisa e a atividade de ensino em cursos de graduação e 
pós-graduação, com seus desafios e perspectivas. Dessa forma, no $5^{\circ}$ Encontro Anual da ABRI, em 2015, organizou-se uma mesa redonda chamada "Pensando a performance das relações internacionais na América Latina: pesquisa, métodos e visões políticas a partir do Teaching, Research and International Politics 2014 (TRIP)", na qual foi possível debater os resultados do TRIP 2014 para a América Latina, e cujas reflexões tornaram premente a necessidade de redigir o presente relatório.

Assim, este documento se divide em seis seções principais, a saber: (i) o perfil das comunidades de RI latino-americanas; (ii) ensino e pesquisa; (iii) metodologias, características epistemológicas e paradigmas das comunidades; (iv) a predominância estadunidense; (v) publicações; (vi) visão dos acadêmicos sobre tendências em política internacional e, por fim, considerações finais.

\section{Perfil das comunidades de RI na América Latina}

Primeiramente, é imprescindível apresentar o universo das comunidades latino-americanas aqui abordadas. Dessa forma, como pode se observar na Tabela I abaixo, nota-se, de antemão, a superioridade, em temos numéricos, das comunidades brasileira e mexicana perante as demais:

Tabela I: Taxa de respondentes

\begin{tabular}{|ccc|}
\hline Países & Respondentes/Total & Taxa de Respostas \\
\hline Argentina & $47 / 82$ & $57 \%$ \\
Brasil & $211 / 321$ & $66 \%$ \\
Chile & $21 / 33$ & $64 \%$ \\
Colômbia & $61 / 115$ & $53 \%$ \\
México & $105 / 284$ & $37 \%$ \\
\hline
\end{tabular}

Fonte: Maliniak et al. TRIP 2014 Faculty Survey

Outro aspecto relevante a ser considerado é a alta taxa de respondentes observada, pois, com exceção do México, que apresentou uma taxa de $37 \%$ de respondentes, os outros países apresentaram taxas maiores que $50 \%$. Somando-se todos eles, apresentaram uma média de $55,4 \%$, com destaque para o Brasil, que, além de compor a maior comunidade da região em termos absolutos, apresentou a mais alta taxa de respondentes da região, com $66 \%$. 


\section{Gráfico I: Evolução do tamanho das comunidades epistêmicas por país}

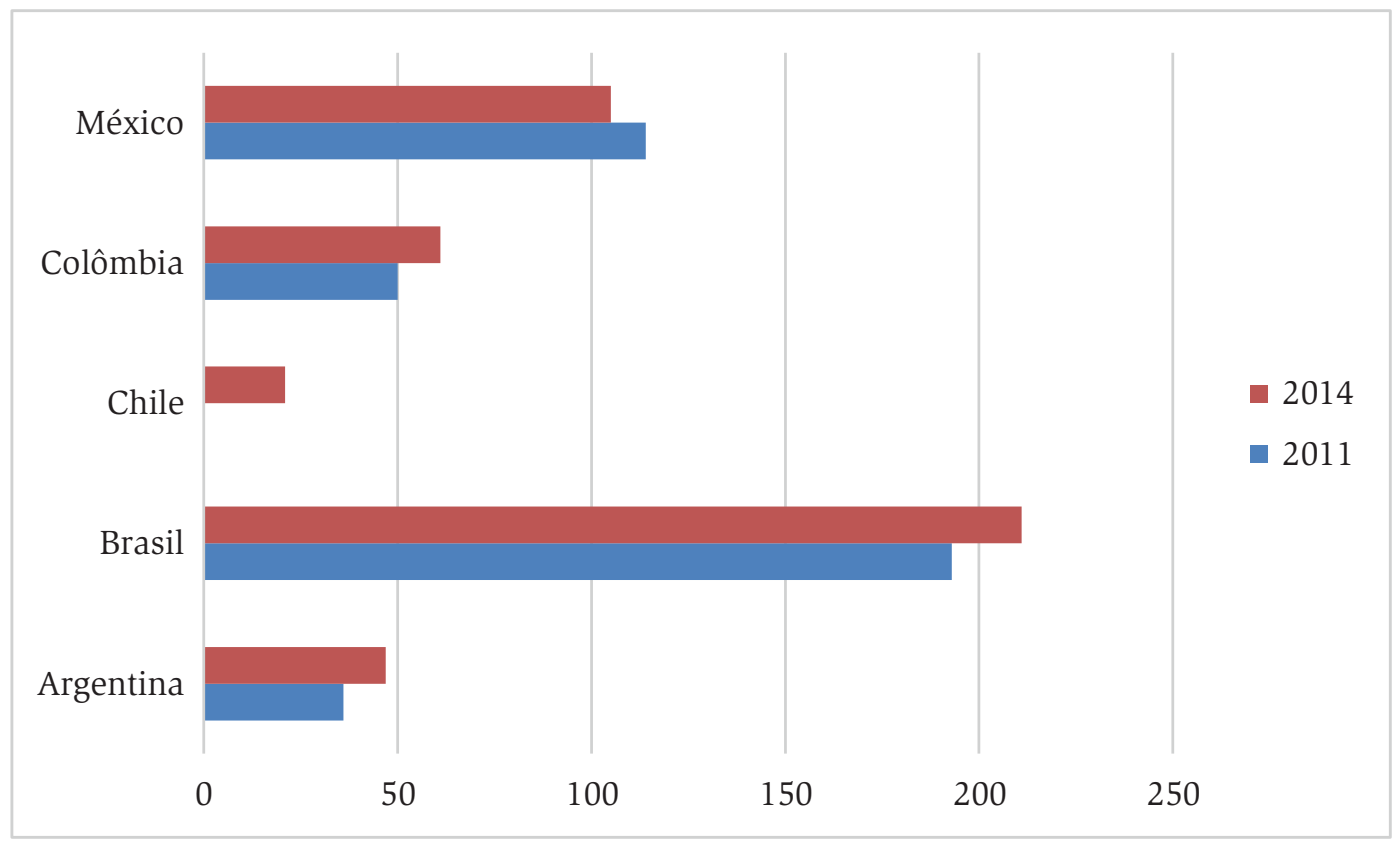

Fonte: Maliniak et al. TRIP 2014 Faculty Survey

Em adicional, é importante ressaltar que a região demonstra uma tendência de crescimento quantitativo de suas comunidades de RI, e percebe-se que a área de Relações Internacionais está em ascensão nesses países, como se observa no Gráfico I, o qual compara os anos de 2011 a 2014. Assim, ao comparar com o TRIP 2011, o que leva em conta que o Chile não participou do survey desse ano, no TRIP 2014 só a comunidade mexicana apresenta uma queda do número de membros na sua comunidade. As causas para tal crescimento podem ser diversas e se referem a questões que vão desde mecanismos mais apurados de identificação de docentes à expansão do ensino privado de relações internacionais e à formação de novos profissionais. Vale, entretanto, ressaltar que o TRIP apenas é aplicado àqueles que se dedicam à docência e à pesquisa, não sendo aplicado àqueles que somente se dedicam à pesquisa.

Tabela II: Percentual de doutores por país

\begin{tabular}{|cc|}
\hline Países & Doutorado \\
\hline Argentina & 50 \\
Brasil & 78,33 \\
Chile & 57,89 \\
Colômbia & 48,33 \\
México & 75,76 \\
\hline
\end{tabular}

Fonte: Maliniak et al. TRIP 2014 Faculty Survey 
Em termos de grau de formação educacional, o Brasil e o México têm a comunidade de doutores mais numerosa, como se observa na Tabela II acima. Da mesma forma, ambas as comunidades são as que apresentam mais membros doutores em termos absolutos. A Colômbia e a Argentina, por sua vez, são os países com menor quantidade de doutores. Em ambos os países, em termos relativos, a metade ou menos da metade da comunidade é de doutores, além do Chile, em que $57,89 \%$ da comunidade é composta por doutores. A partir desses dados, é possível inferir que existem desequilíbrios na formação de doutores entre as comunidades de RI na América Latina. Ademais, em termos gerais, é possível afirmar que existe um déficit de formação de doutores na comunidade de RI latino-americana, pois mesmo o índice do Brasil e do México, com média de $77 \%$ de doutores entre os respondentes, não é um índice satisfatório quando se considera que nos Estados Unidos o percentual de doutores é de 95,7\%, na Inglaterra é de $97,57 \%$, e na Turquia é de $93,48 \%$.

Tabela III: Percentual de homens e mulheres por país

\begin{tabular}{|cccccc|} 
& Argentina & Brasil & Chile & Colômbia & México \\
\hline Mulheres & 43,48 & 34,93 & 26,32 & 36,67 & 38,46 \\
Homens & 56,52 & 65,07 & 73,68 & 63,33 & 61,54 \\
\hline
\end{tabular}

Fonte: Maliniak et al. TRIP 2014 Faculty Survey

No que se refere ao gênero, a comunidade de relações internacionais na América Latina é fortemente masculina, pois, em média, quase dois terços pertence a esse gênero. No entanto, nesse aspecto, a comunidade latino-americana segue o mesmo padrão de gênero global. O país que apresenta uma relação de gênero mais equilibrada é a Colômbia ( 56 a $43 \%$, a favor da masculina) e o país que apresenta um maior desequilíbrio a favor do gênero masculino é o Chile $(78,63 \%)$.

\section{Tabela IV: Percentual de faixa etária por país}

\begin{tabular}{|cccccc|}
\hline & Argentina & Brasil & Chile & Colômbia & México \\
\hline$<35$ & 10,87 & 20,77 & 10,53 & 30 & 4,04 \\
$35-44$ & 36,96 & 35,27 & 31,58 & 36,67 & 25,25 \\
$45-54$ & 21,74 & 22,71 & 21,05 & 16,67 & 24,24 \\
$55-64$ & 13,04 & 13,53 & 5,26 & 15 & 31,31 \\
$65+$ & 17,39 & 7,73 & 31,58 & 1,67 & 15,15 \\
\hline
\end{tabular}

Fonte: Maliniak et al. TRIP 2014 Faculty Survey. 
Com relação à faixa etária, em torno de um terço da comunidade de RI se localiza entre 35 a 44 anos, com exceção do México, em que essa faixa responde por apenas $25,25 \%$. O México apresenta a comunidade com faixa de idade mais alta, pois um terço de sua comunidade tem entre 55 a 64 anos. No entanto, o país que apresenta a faixa etária mais idosa (mais de 65 anos) é o Chile, com 31,58\% de sua comunidade. Já a Colômbia, e em menor medida o Brasil, são os países que apresentam comunidades mais jovens (menos de 35 anos).

A comunidade de RI latino-americana é dividida quanto à sua percepção étnica. Nas comunidades argentina e chilena, uma média de $80 \%$ dos pesquisadores se considera brancos e apenas $11 \%$ se consideram mestiços. Nas comunidades colombiana e mexicana, em média, $47 \%$ se consideram brancos, e $48 \%$ se consideram mestiços. Vale ressaltar que essa questão não foi proposta pelo survey aos respondentes do Brasil.

Partindo para o campo das percepções de mundo, o survey do TRIP pergunta sobre o posicionamento ideológico dos respondentes, se é mais alinhado a percepções de esquerda ou de direita e os resultados para as comunidades latino americanas são interessantes, como pode se observar no Gráfico II:

\section{Gráfico II: Posição ideológica em assuntos econômicos e sociais}

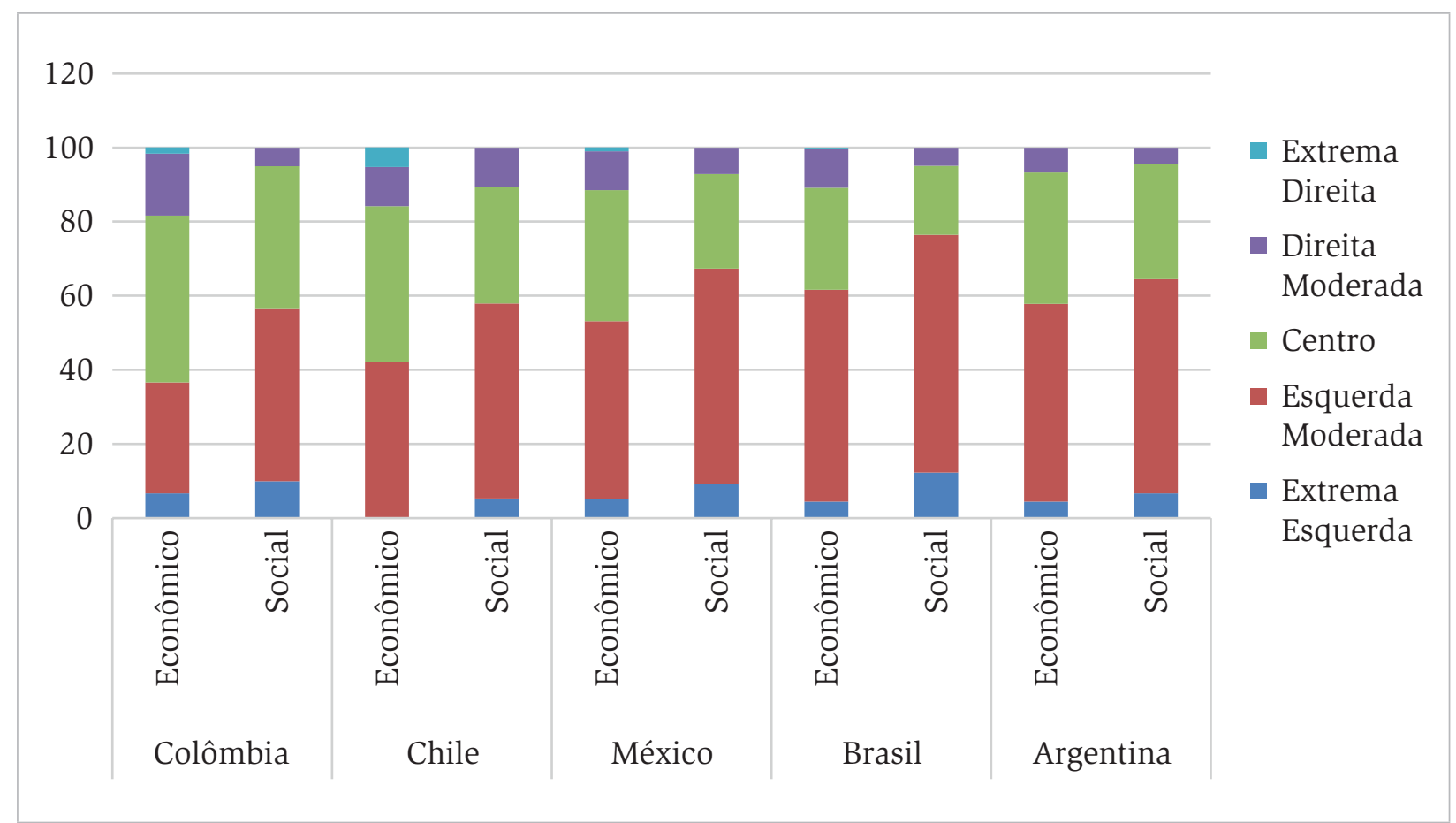

Fonte: Maliniak et al. TRIP 2014 Faculty Survey 
A partir dos resultados, foi possível afirmar que os estudiosos latino-americanos se percebem como de centro-esquerda, mesmo tendo algumas variações quanto à natureza do assunto. Por exemplo, a sua posição tende a estar mais perto do centro quando as questões são mais de natureza econômica do que sociais, como é mostrado no gráfico.

Posições radicais como “muito à direita” ou “muito à esquerda” não são comuns entre os estudiosos, ainda que haja mais respondentes que se definem como muito à esquerda do que como muito à direita, especialmente em questões sociais. Vale ressaltar que os países Argentina, Brasil e México mantém uma tendência próxima, moderada economicamente e à esquerda em assuntos sociais; já a Colômbia apresenta uma ligeira mudança, dado que em 2011 percentuais significativos (cerca de $20 \%$ ) se definiram como “um pouco à direita”, tanto nas questões econômicas e sociais, em contraste com levantamento de 2014 que mostrou $18 \%$ apenas nos aspetos econômicos; e o Chile apresenta um comportamento semelhante, exceto pelo fato de que, em questões econômicas, ninguém se tenha definido como “muito à esquerda”. O Brasil é o país em que a comunidade de RI tende a mostrar-se mais à esquerda em questões sociais (em torno de 12\%).

\section{Ensino e Pesquisa}

\section{Ensino}

Conforme aqui já foi explicitado, um dos dois pilares do projeto TRIP é a atividade de docência. O survey, nesse sentido, traz importantes insights tanto em termos de distribuição de conteúdos, e sua diferenciação para os níveis de graduação, mestrado e doutorado, quanto na busca por captar a percepção dos docentes quanto à interdisciplinaridade das relações internacionais e seus desdobramentos na condução das atividades em sala de aula. 


\section{Gráfico III: Cursos lecionados por docentes latino-americanos}

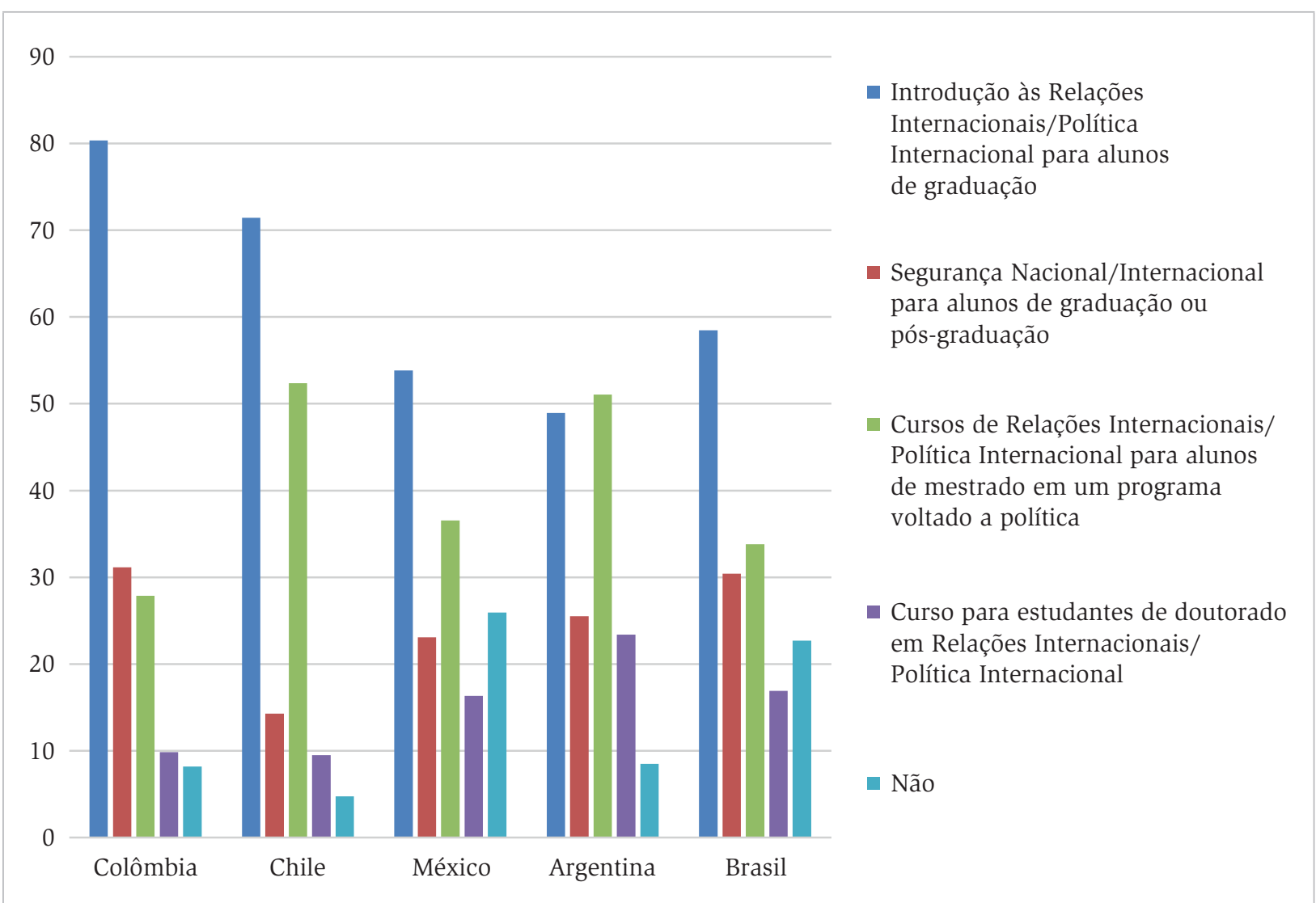

Fonte: Maliniak et al. TRIP 2014 Faculty Survey

Assim, no que se refere ao ensino, a maior parte dos pesquisadores da Colômbia e Brasil têm ensinado cursos introdutórios para Relações Internacionais para a graduação. No caso da Argentina, os entrevistados afirmam ensinar mais cursos introdutórios para o mestrado do que para a graduação.

É importante destacar que a quantidade de pesquisadores que têm ensinado em cursos de doutorado em relações internacionais ou política global tem crescido na região. Mesmo que tal índice seja menor em relação à graduação e ao mestrado, os índices para o México, Brasil e Argentina indicam que, pelo menos, 16\% de seus professores têm lecionado em cursos de doutorado sobre aquela temática, o que sugere que há um crescimento dos programas de doutorado em relações internacionais ou áreas afins na região, ou pelo menos nesses países, com destaque para a Argentina, onde esse índice ultrapassa $20 \%$. 


\section{Gráfico IV: Desenho de cursos introdutórios na graduação}

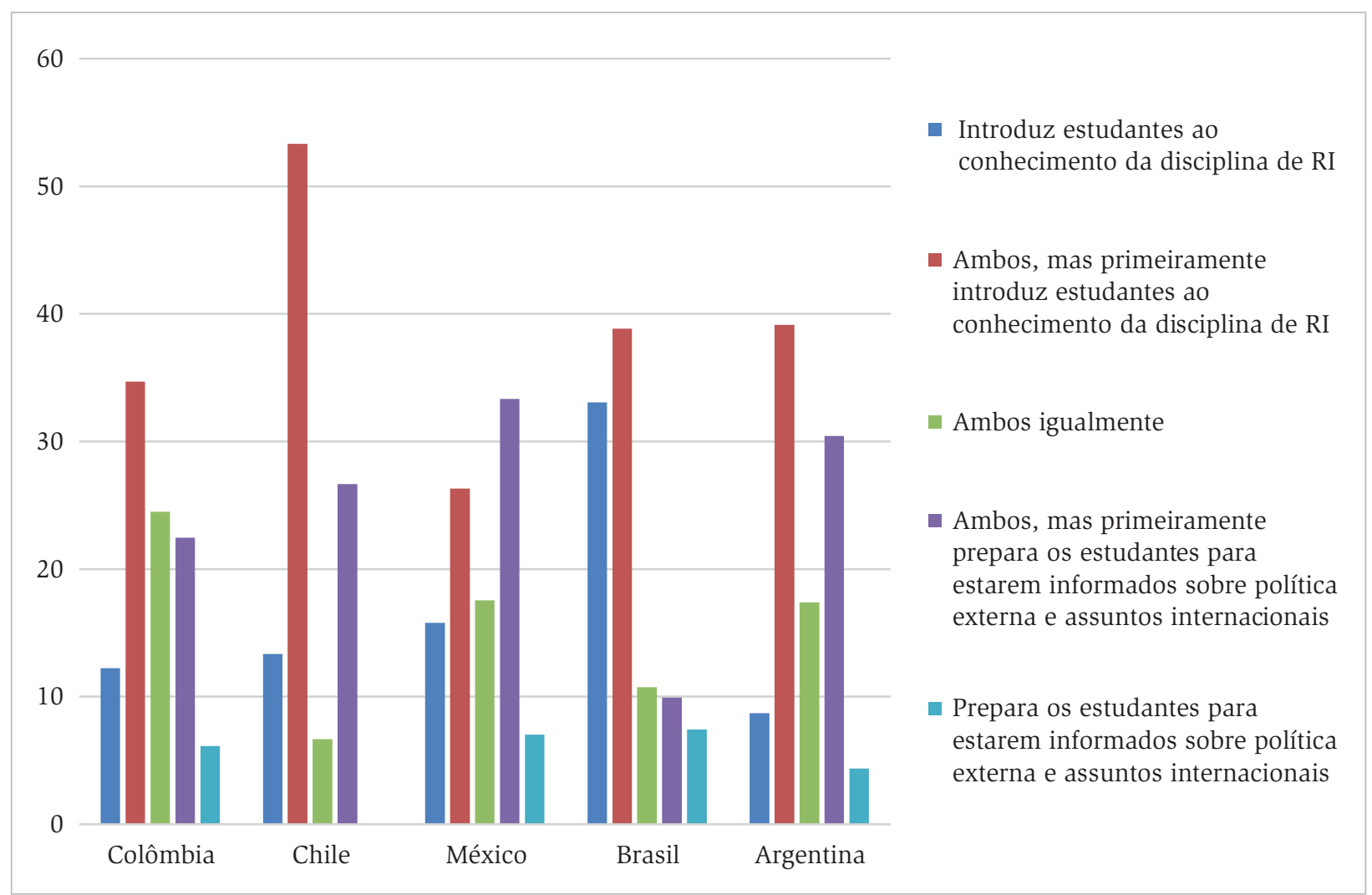

Fonte: Maliniak et al. TRIP 2014 Faculty Survey.

No que se refere à forma como as cinco comunidades organizam os cursos introdutórios de RI, há diferenças significativas entre os cursos de graduação e mestrado. No caso da graduação, conforme pode ser observado no Gráfico IV acima, a maioria dos entrevistados na Colômbia $(34,6 \%)$, Chile $(53,3 \%)$, Brasil $(38,8 \%)$ e Argentina $(39,1 \%)$ afirmam organizarem seus cursos para introduzir os alunos à disciplina e para informá-los sobre a política externa e questões internacionais, porém principalmente para apresentar-lhes a disciplina. Já os docentes mexicanos $(33,3 \%)$, por sua vez, afirmam fazerem o mesmo, porém com maior inclinação para informar os estudantes sobre temas e questões internacionais. 


\section{Gráfico V: Desenho de cursos introdutórios no Mestrado}

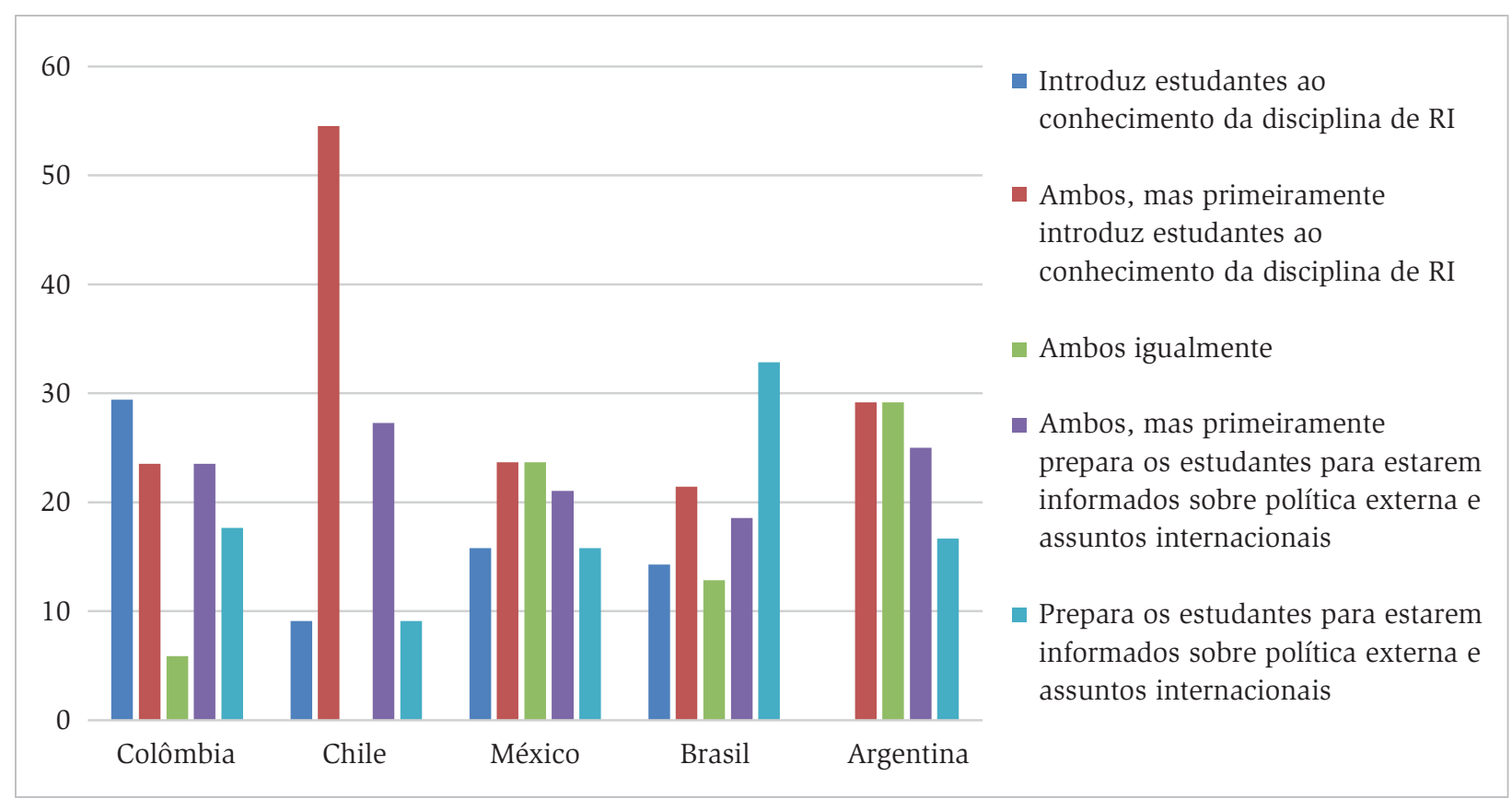

Fonte: Maliniak et al. TRIP 2014 Faculty Survey.

Já no caso dos cursos de mestrado, não parece haver consenso entre as cinco comunidades, conforme se observa no Gráfico V acima. Com relação à forma como planejam seus cursos, no caso da Colômbia, grande parte $(29,4 \%)$ da comunidade desenha os programas de forma a apresentar aos alunos a disciplina das relações internacionais, mas há um percentual significativo $(17,6 \%)$ que desenha os programas para informar os estudantes sobre questões de política externa e temas internacionais. Os pesquisadores do México são divididos quanto a tal aspecto: 23,6 \% inclinam-se a prestar a mesma atenção à formação disciplinar e questões de política internacional; e o mesmo percentual tenta manter ambos os aspectos em seus cursos, mas dando maior ênfase aos aspectos disciplinares; e um percentual significativo $(15,7 \%)$ elabora seus programas de tal maneira a apresentar aos alunos a disciplina ou para informá-los sobre política internacional.

Já no Brasil predomina uma preparação dos programas com intuito de informar os alunos sobre a política externa e questões internacionais $(32,8 \%)$, enquanto na Argentina um percentual aproximado $(29,1 \%)$ afirma que dá a mesma importância para as duas tendências, mas ligeiramente privilegia apresentar a disciplina. Por fim, os docentes do Chile $(54,5 \%)$ mantiveram o mesmo padrão que apresentaram para o nível de graduação.

Em geral, os resultados apontam que os estudiosos latino-americanos estão conscientes da importância de preparar os estudantes tanto para o exercício da 
academia quanto para a prática da política internacional. Em outras palavras, há uma percepção nessas comunidades de que deve haver uma ponte entre o mundo acadêmico e o mundo político, ambiente dos processos de tomada de decisão.

Com relação às outras disciplinas ministradas, observa-se que cursos de segurança nacional ou internacional estão entre os mais lecionados na Colômbia e no Brasil, o que poderia ser um sinal da importância desses temas nos currículos acadêmicos nesses países ou mesmo a proliferação de cursos dessa natureza poderia atentar para a importância de tais temáticas nas agendas políticas desses respectivos países.

Ademais, observa-se que nos cursos de segurança internacional são ministrados tópicos diferentes, mas ainda é possível encontrar tendências comuns de predomínio de processos, como a relação entre terrorismo, atores privados (incluindo militares) e segurança. Gênero e doença/saúde global, por seu lado, são os temas que recebem menos atenção pelas cinco comunidades. O Chile torna-se um caso interessante, pois os conteúdos mais relevantes são a inteligência, os atores privados, escassez de recursos e terrorismo (66\% em todos os casos), em contraste com questões como as alterações climáticas ou de gênero que não foram escolhidos pelos respondentes.

Mesmo que a docência em programas de doutorado seja a menos frequente entre os respondentes, o survey de 2014 incluiu uma pergunta sobre a organização do conteúdo em cursos de doutorado. E a tendência entre os estudiosos latino-americanos é de organizá-lo de acordo com paradigmas ou escolas de pensamento; no entanto, no Brasil, boa parte dos estudiosos (38,3\%) prefere fazê-lo em função de dúvidas ou problemas de pesquisa.

Nesse ínterim, apenas na Colômbia é possível encontrar um grupo significativo (16\%) que organiza o conteúdo em termos de “abordagens racionais vs. não racionais”, enquanto, no México e no Brasil (29,4\%), os docentes fazem o mesmo de acordo com os níveis de análise. Por fim, diferentes áreas temáticas também parecem ser uma forma importante de organizar cursos de doutorado na Colômbia (16,6\%), México (11,7\%), Brasil (12,2\%) e Argentina (27,2\%). 
Gráfico VI: Opinião sobre ensino de Relações Internacionais enquanto um campo interdisciplinar ou subárea da Ciência Política

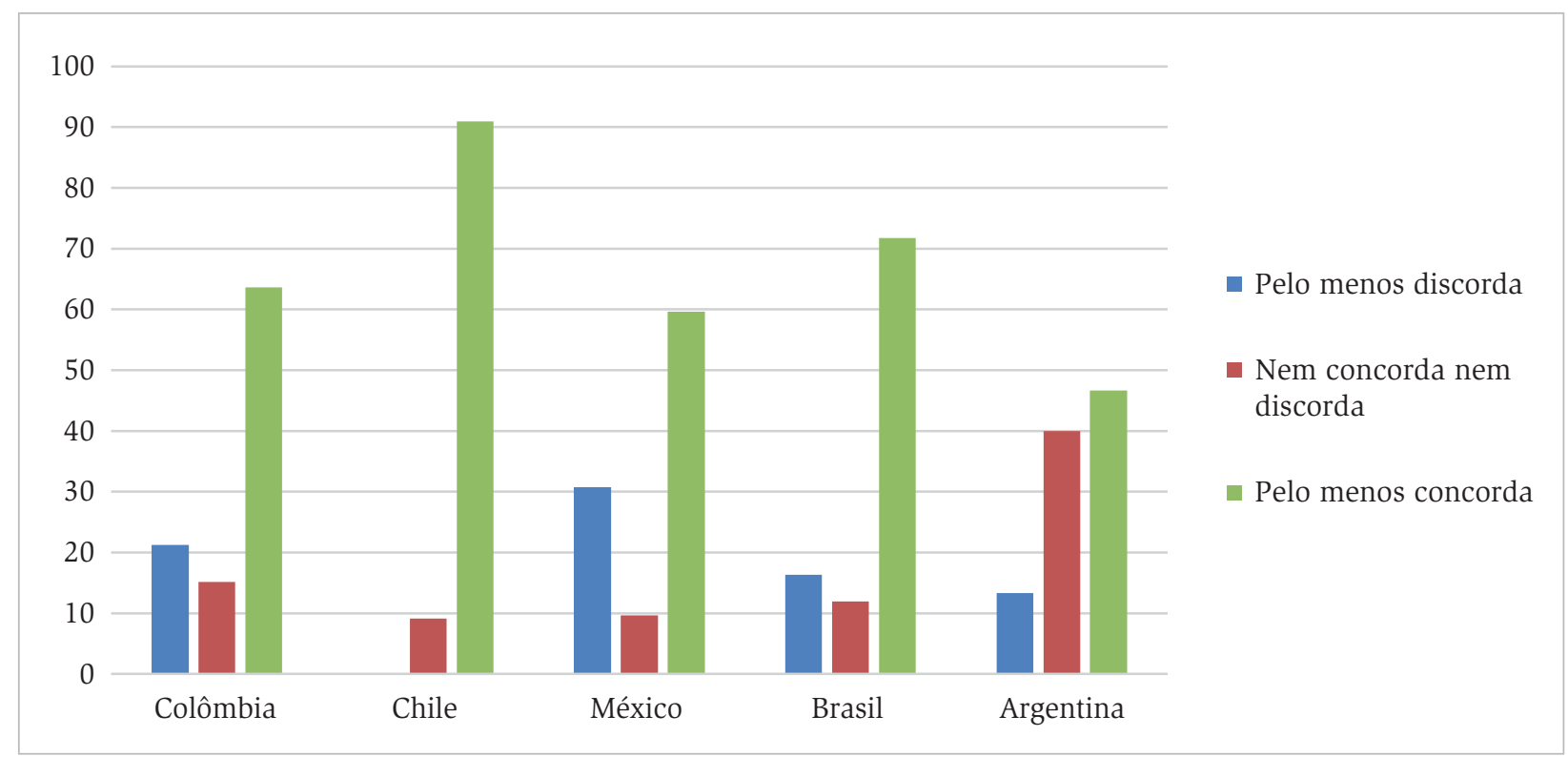

Fonte: Maliniak et al. TRIP 2014 Faculty Survey.

O survey de 2014 possibilitou uma reflexão sobre o quanto os pesquisadores consideram importante a forma como a área de relações internacionais é percebida em sua interdisciplinaridade e de que forma é organizada no nível institucional das universidades. Como pode se observar no gráfico acima, a maioria dos estudiosos, nos cinco casos, concorda com a ideia de ensinar relações internacionais como uma disciplina interdisciplinar, em vez de ensiná-la enquanto um subcampo da ciência política. O Chile, por sua vez, é o caso em que os docentes mais concordam com a interdisciplinaridade da área e o México foi o país que apresentou um maior índice de discordância com tal ideia. 
Gráfico VII: Programas de doutorado em Relações Internacionais

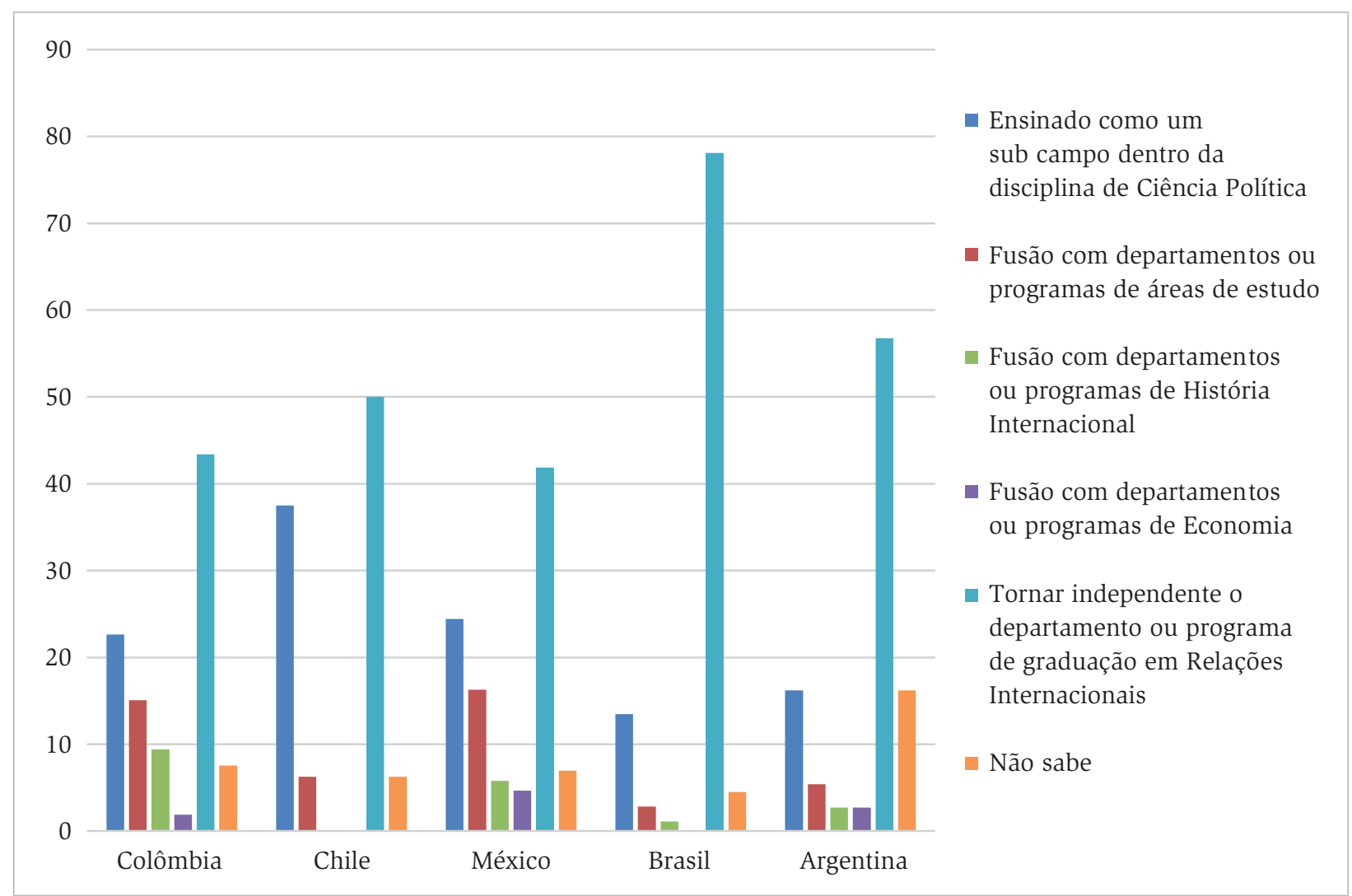

Fonte: Maliniak et al. TRIP 2014 Faculty Survey.

No âmbito dos programas de doutorado, os docentes consideram que programas de relações internacionais de tal grau deveriam tornar-se programas de departamento ou com algum grau de autonomia, com destaque para os docentes brasileiros, os quais defendem, com um percentual de quase 80\%, tal opção, segundo dados do Gráfico VII acima. A segunda opção é para que a disciplina seja ensinada como um subcampo dentro da ciência política, ao passo que a terceira possibilidade mais escolhida seria para se fundir com estudos de área de departamentos ou programas. As opções menos atrativas, em todos os casos, são mesclar-se com departamentos de economia e de história, mostrando, assim, uma forte preferência para que a área se estabeleça de forma autônoma e independente das demais, ou mesclando-se com departamentos de ciência política, como tem sido a tendência norte-americana.

\section{Pesquisa}

O segundo pilar do Projeto TRIP se refere à atividade de pesquisa. Nesse sentido, o survey buscou colher impressões diversas quanto aos temas pesquisados, 
áreas de interesse e afins, para que se possa desenhar um quadro analítico abrangente de quais temas estão mobilizando pesquisadores latino-americanos e se há convergências ou dissonâncias em tais escolhas.

Tabela V: Principais áreas e temas de pesquisa por país

\begin{tabular}{|c|c|c|c|c|c|}
\hline & Argentina & Brasil & Chile & Colômbia & México \\
\hline $\begin{array}{l}\text { Principal } \\
\text { área de } \\
\text { pesquisa }\end{array}$ & $\begin{array}{c}\text { Relações } \\
\text { Internacionais de } \\
\text { uma região/país } \\
\text { particular }\end{array}$ & $\begin{array}{c}\text { Segurança } \\
\text { Internacional/ } \\
\text { Global }\end{array}$ & $\begin{array}{c}\text { Política Externa } \\
\text { chilena }\end{array}$ & $\begin{array}{c}\text { Relações } \\
\text { Internacionais de } \\
\text { uma região/país } \\
\text { particular, } \\
\text { Teoria de } \\
\text { Relações } \\
\text { Internacionais }\end{array}$ & $\begin{array}{c}\text { Política Externa } \\
\text { Mexicana }\end{array}$ \\
\hline $\begin{array}{l}\text { Segunda } \\
\text { principal } \\
\text { área de } \\
\text { pesquisa }\end{array}$ & $\begin{array}{c}\text { Política Externa } \\
\text { Argentina }\end{array}$ & $\begin{array}{c}\text { Relações } \\
\text { Internacionais de } \\
\text { uma região/país } \\
\text { particular }\end{array}$ & $\begin{array}{c}\text { Relações } \\
\text { Internacionais de } \\
\text { uma região/país } \\
\text { particular }\end{array}$ & $\begin{array}{c}\text { Relações } \\
\text { Internacionais de } \\
\text { uma região/país } \\
\text { particular }\end{array}$ & $\begin{array}{c}\text { Relações } \\
\text { Internacionais de } \\
\text { uma região/país } \\
\text { particular }\end{array}$ \\
\hline
\end{tabular}

Fonte: Maliniak et al. TRIP 2014 Faculty Survey.

Dessa forma, quanto aos temas escolhidos, percebe-se que os interesses temáticos de investigação são diversificados nas diferentes comunidades latino-americanas, embora concentrados em um leque não muito amplo de assuntos. Quanto à principal área de estudo dentro das RIs, os pesquisadores argentinos são mais inclinados por "relações internacionais de uma determinada região ou país” com um pouco menos de atenção para temas como política externa e política externa dos Estados Unidos, teoria de Relações Internacionais ou economia política internacional. Já no caso do Brasil, segurança internacional e global é de longe a principal área de estudo, embora política externa brasileira também tenha preferência numa parte importante da comunidade de RI do país. Enquanto no Chile, os estudos de política externa do país é também de longe o principal assunto investigado em RI, seguido por teoria de Relações Internacionais, porém, em proporção menor. Na Colômbia, por sua vez, as áreas "relações internacionais de uma determinada região ou país” e teoria de Relações Internacionais dividem as duas principais escolhas da comunidade de RI daquele país. Finalmente, no caso do México, os temas de política externa, economia política internacional e "relações internacionais de uma determinada região ou país" se apresentam nessa sequência. 
Os dados sugerem que pesquisadores da região latino-americana priorizam, de modo geral, a pesquisa da política externa de seus respectivos países, o que pode sugerir ou que estejam buscando mais protagonismo e participação no debate interno sobre as políticas externas regionais ou mesmo que suas pesquisas reflitam um maior protagonismo de seu país no cenário internacional.

Quanto ao destaque que pesquisadores brasileiros dão ao tema da segurança internacional, esse pode se relacionar à maior projeção do país na política internacional, sobretudo nos últimos 15 anos, quando o país se tornou uma das dez maiores economias do mundo, período que coincidiu também com a renovação de seu aparato militar e um maior comprometimento com a segurança regional, especialmente com a forte participação em operações de paz das Nações Unidas. Tais fenômenos podem ter estimulado a comunidade local, para além de observar a política externa de seu país, a pesquisar temas de segurança internacional em geral.

\section{Gráfico VIII. Percentual dos que pesquisam América do Sul como região prioritária}

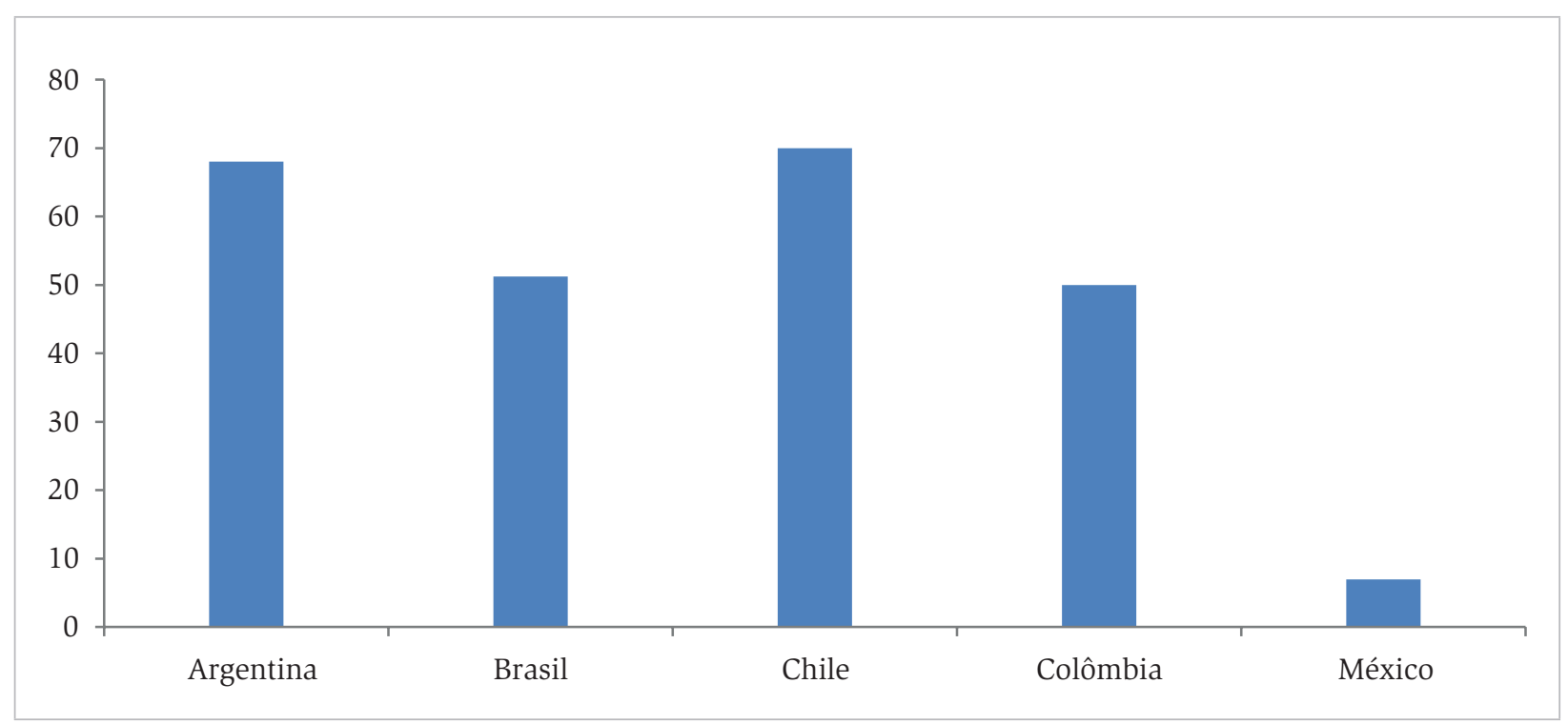

Fonte: Maliniak et al. TRIP 2014 Faculty Survey.

A maior parte das comunidades, em quase todos os países pesquisados, apresenta como principal área de estudo a América do Sul, como se observa no gráfico VIII acima, com exceção do México, cuja preferência é América do Norte (sem incluir o próprio México). A Argentina pesquisa a América do Sul num percentual de $68 \%$, o Chile e a Colômbia apresentam percentual de $70 \%$ e o Brasil um percentual de $51 \%$. Porém, inclusive no caso do México, a região 
sul-americana aparece como a primeira quando a pergunta do survey se refere a quais outras regiões (além da principal) o investigador pesquisa. Pesquisar América Latina é quase sinônimo de pesquisar América do Sul. Em casos como o Brasil e o Chile, por exemplo, regiões como América Central e Caribe apresentam índice de interesse de pesquisa de $0 \%$, ou seja, o interesse de pesquisa nessas sub-regiões é praticamente inexistente.

\section{Métodos, epistemologias e paradigmas nas comunidades latino-americanas}

O projeto TRIP possibilita uma rica reflexão no que se refere às opções metodológicas e epistemológicas ao se produzir cientificamente. O survey, nesse sentido, lança mão de importantes questionamentos quanto às opções de método, quanto ao positivismo, quanto à percepção ou não de racionalidade nos atores, e, por fim, quanto às escolhas paradigmáticas (escolas teóricas) feitas pelos acadêmicos da região. Os resultados colhidos permitem traçar um diagnóstico importante sobre qual é o estado da arte da comunidade epistêmica latinoamericana de Relações Internacionais, bem como identificar tendências futuras quanto a essas comunidades.

\section{Método}

Tabela VI: Principais métodos de pesquisa por país

\begin{tabular}{|cccccc|}
\hline & Argentina & Brasil & Chile & Colômbia & México \\
\hline Principal método & Análise & Análise & Análise & Análise & Análise \\
de pesquisa & Qualitativa & Qualitativa & Qualitativa & Qualitativa & Qualitativa \\
Segundo principal & Análise & Análise & Análise & Análise & Análise \\
método de pesquisa & Política & Política & Política & Política & Política \\
\hline
\end{tabular}

Fonte: Maliniak et al. TRIP 2014 Faculty Survey

Quanto às escolhas de método, observa-se nas cinco comunidades a opinião, bastante acentuada por sinal, de que a metodologia qualitativa é a principal ferramenta de pesquisa utilizada nas pesquisas da região. Com exceção do México e do Brasil, o restante dos países utilizam metodologias qualitativas num 
percentual que vai de $60 \%$ a $70 \%$. Um dado importante é que a metodologia de análise política (policy analysis) consegue superar a de métodos quantitativos, algo contrafatual à ideia de que atualmente existe uma forte penetração dos métodos quantitativos em comunidades de RIs do mundo em desenvolvimento.

E mais significativo ainda é constatar que o método formal (modelos formais), outro método sobre o qual recai crença de que haveria muitos adeptos na América Latina, também tem muito pouco espaço, não passando de $5 \%$ de aceitação no melhor dos casos (o Chile). Observam-se, nesse sentido, casos de comunidades que até manifestam não utilizar tais métodos (México, Colômbia e Brasil). Por fim, vale ressaltar a importância do conjunto desses dados, uma vez que se evidencia na região uma resistência ainda latente ao método quantitativo.

\section{Epistemologia}

\section{Gráfico IX: Posição quanto ao positivismo por país}

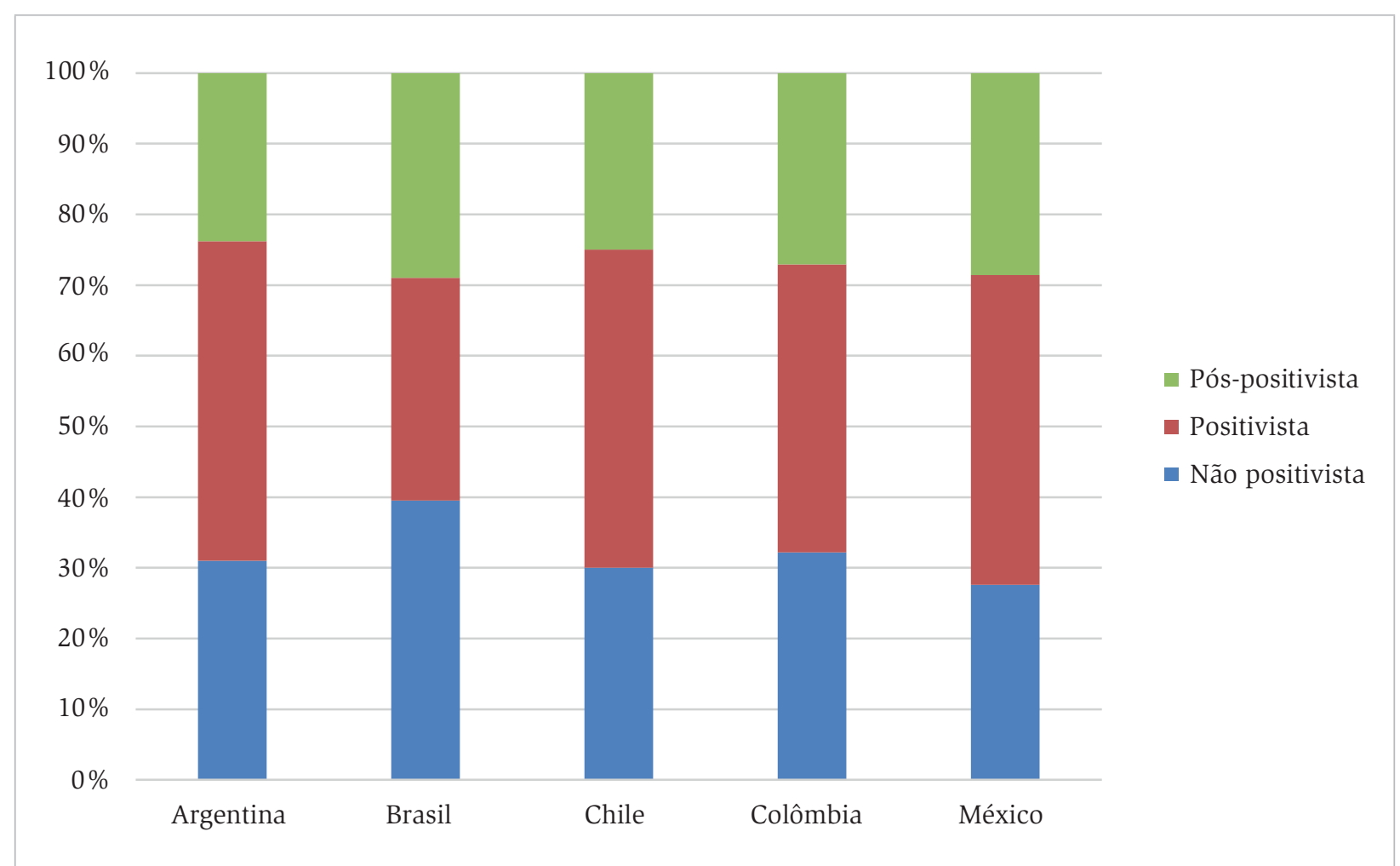

Fonte: Maliniak et al. TRIP 2014 Faculty Survey

Em termos epistemológicos, observa-se uma predominância do positivismo, como se observa no Gráfico IX. Em quatro dos países latino-americanos: Argentina, Chile, Colômbia e México, o positivismo detém a preferência majoritária. Como já havia acontecido no TRIP 2011, o Brasil se distancia dessa tendência porque é 
o único dos países em que os “não positivistas” superam os positivistas. O Brasil também se apresenta como o país com maior número de pós-positivistas (embora próximos em percentual dos outros países). No entanto, é importante sublinhar que em termos gerais os dados tendem a reforçar uma pluralidade epistemológica entre as comunidades latino-americanas de RI, isso porque a predominância positivista é equilibrada pelo alto percentual das escolhas pelo "não positivismo" e o "pós-positivismo”, pois, em geral, nas cinco comunidades, somam uma média de 55 a $60 \%$ das escolhas epistemológicas, gerando assim uma tendência a um certo hibridismo epistemológico.

\section{Gráfico X: Percentual daqueles que empregam tanto perspectivas racionalistas quanto partem de abordagens alternativas, que não se baseiam na racionalidade dos atores.}

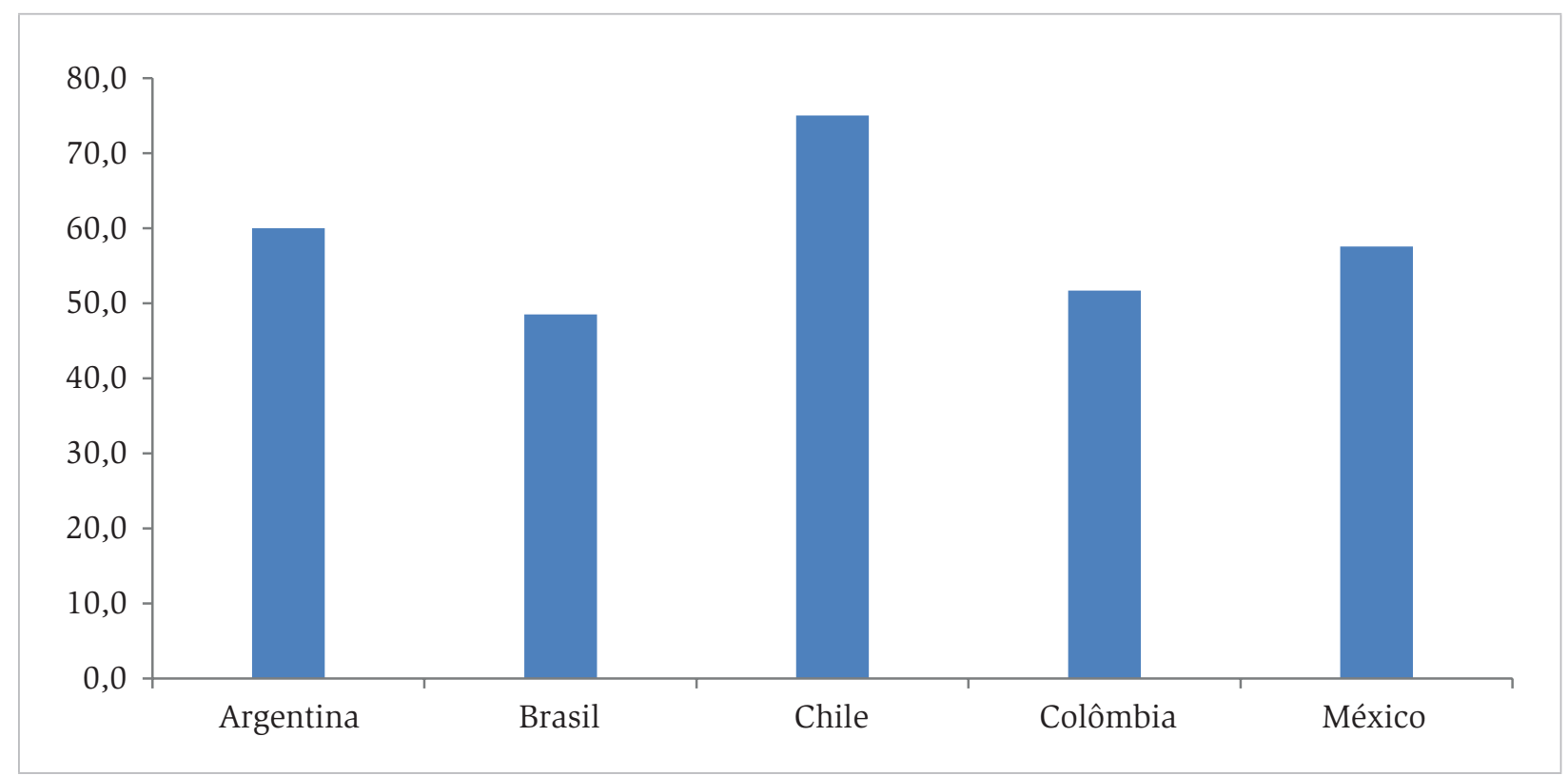

Fonte: Maliniak et al. TRIP 2014 Faculty Survey.

Nesse mesmo aspecto epistemológico, os dados parecem contrariar a percepção segundo a qual a comunidade latino-americana de RI é fortemente racionalista. Existe uma forte tendência entre as cinco comunidades em declarar (em altos índices que vão de $51 \%$ a $70 \%$ ) que suas pesquisas se baseiam tanto em pressupostos de racionalidade dos atores, bem como em abordagens alternativas, que não necessariamente assumem a racionalidade dos atores. Assim, é significativo também que, em média, quase $20 \%$ dos entrevistados na América Latina declarem que não assumem a racionalidade dos atores. Em resumo, quanto aos aspectos epistemológicos, as comunidades latino-americanas parecem seguir um padrão 
pluralista que ora se apoia na racionalidade dos atores, ora não presume a racionalidade dos mesmos.

Ademais, o survey possibilita a indicação de preferências no que tange às escolhas paradigmáticas dos acadêmicos, o que pode reforçar algumas das tendências observadas nas escolhas metodológicas e epistemológicas observadas acima.

\section{Paradigmas}

\section{Gráfico XI. Escolhas paradigmáticas atuais por país}

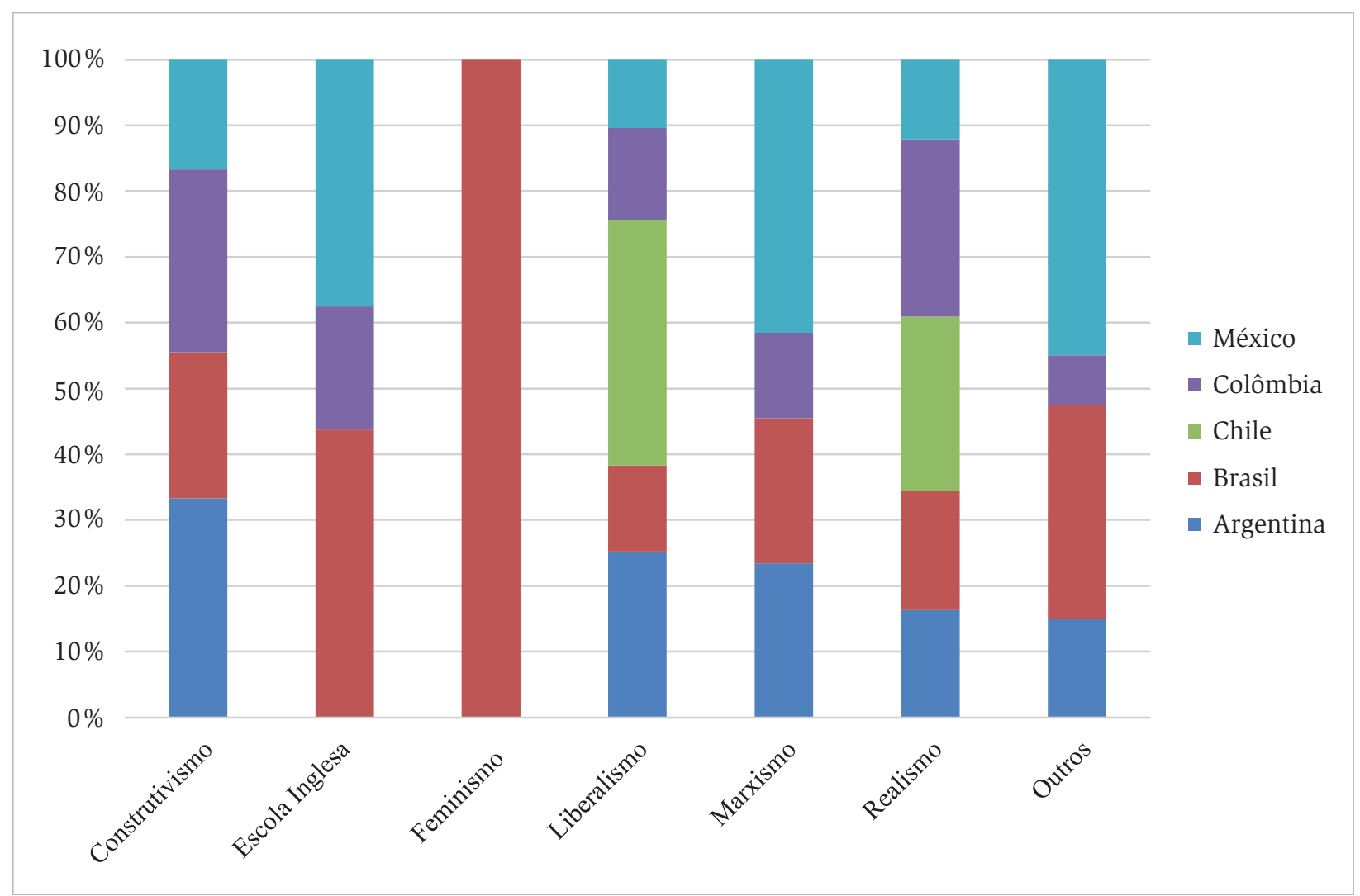

Fonte: Maliniak e al. TRIP 2014 Faculty Survey.

Em termos de paradigmas, com exceção do México e do Brasil, as comunidades de RI da América Latina se declaram majoritariamente construtivistas, como se pode verificar no Gráfico XI acima. No México, as preferências pelo realismo são levemente superiores às preferências pelo construtivismo. Porém, é importante ressaltar novamente que essas preferências construtivistas se inscrevem novamente dentro de um pluralismo paradigmático. Com exceção do Chile, o realismo continua a ter uma boa utilização entre as comunidades latino-americanas, e, em alguns casos, como Argentina e Brasil, o percentual dos que utilizam o paradigma realista não chega a estar tão distante dos que usam o paradigma construtivista. Da mesma 
forma, porém em menor medida, o liberalismo, a escola inglesa e o marxismo (este último com a exceção do Chile) têm também uma razoável aceitação.

Quanto aos paradigmas, observa-se que parece existir certo esgotamento do uso exclusivo, ou excludente, dos paradigmas. O percentual dos que afirmam "Eu não uso análise paradigmática" é relevante nas cinco comunidades, como se observa no Gráfico XI. Porém, novamente, as comunidades parecem afirmar com isso que suas análises não se atrelam necessariamente a um único paradigma.

\section{Gráfico XII: Utilização de análise paradigmática por país}

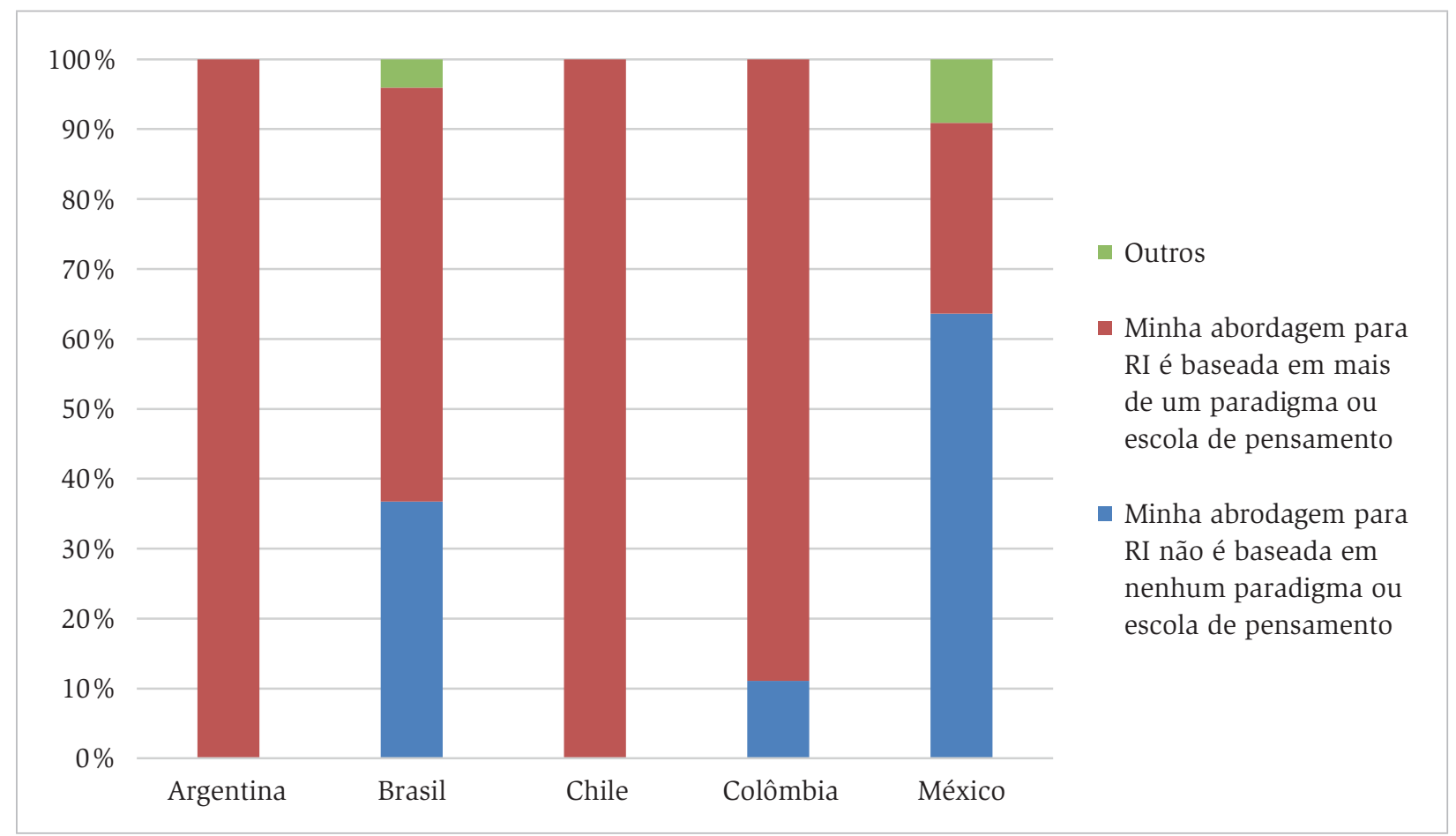

Fonte: Maliniak et al. TRIP 2014 Faculty Survey

De acordo com o Gráfico XII acima, em quatro das comunidades (com exceção do México), majoritariamente, e em altos percentuais, as respostas apontam que "Meu enfoque às RIs é baseado em mais de um paradigma ou escola de pensamento". Em alguns casos, como Argentina e Chile, $100 \%$ da comunidade adota essa posição, e, em casos, como Brasil e Colômbia, esse percentual varia de $59 \%$ a $88 \%$.

Um aspecto relevante é que, embora as comunidades tenham se afastado do uso exclusivo de paradigmas e algumas escolas tradicionais continuem a ter um bom aproveitamento nas análises, percebe-se que tem havido um processo de "migração" de escolas tradicionais de pensamento, como o realismo, liberalismo e o marxismo, para outras não tradicionais como construtivismo e escola inglesa 
ou para "outros" paradigmas; ou também, simplesmente, pesquisadores que abandonaram o paradigma tradicional, mas afirmam que "não usam análises paradigmáticas". Entre as escolas tradicionais, essa migração deu-se mais fortemente do realismo para outras escolas. Quatro das comunidades estudadas (Argentina, Brasil, Colômbia e Chile) começaram a partir de uma forte base do realismo. Sendo assim, percebe-se que, de fato, mais de uma geração de acadêmicos foi socializada inicialmente no realismo na disciplina de RI na região, conforme se observa no Gráfico XIII abaixo:

\section{Gráfico XIII: Escolhas paradigmáticas iniciais por país}

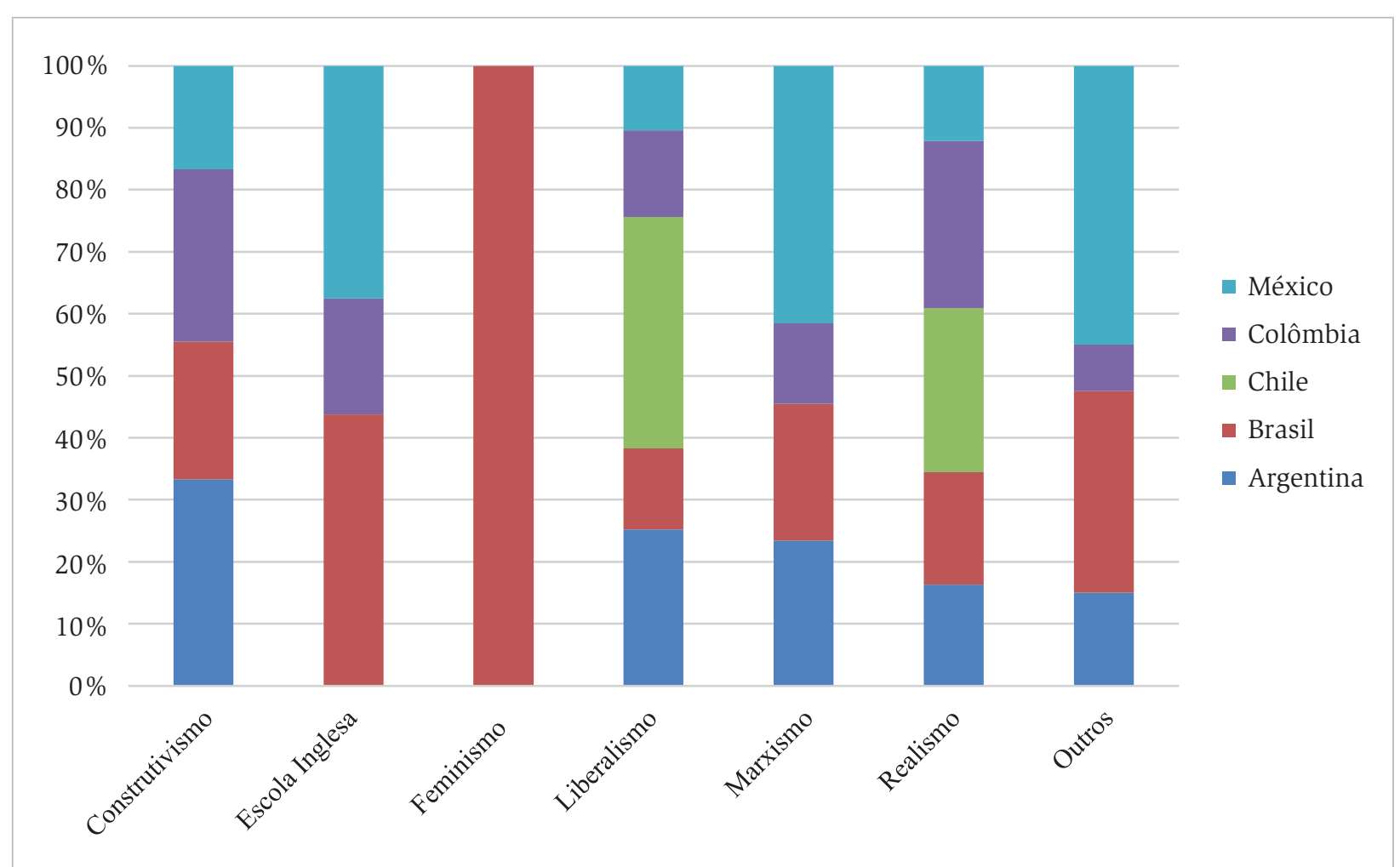

Fonte: Maliniak e al. TRIP 2014 Faculty Survey

Em média, nas cinco comunidades, mais de $27 \%$ dos membros pesquisadores mudaram de paradigma, embora isso seja mais forte em países como Colômbia e México, onde quase um terço da comunidade mudou de paradigma. Também é significativo que, apesar da forte orientação que prevalece na disciplina para o uso de paradigmas, quase um quarto da comunidade latino-americana afirma que nunca usou paradigma de análise. Tal constatação não é irrelevante, pois pode nos levar à seguinte reflexão: análises mais sofisticadas poderiam dispensar o uso de paradigmas? 


\section{A Influência Estadunidense na Disciplina}

O survey do TRIP 2014 questionou os acadêmicos a respeito do fecundo debate inaugurado em finais da década de 1970 por Stanley Hoffman e que se referia ao fato de a disciplina de Relações Internacionais ser ou não uma disciplina dominada basicamente pela produção, paradigmas e metodologias norte-americanos.

Nos resultados, percebe-se novamente uma dissonância entre os países, especialmente no que se refere à posição do Brasil, e, em alguma medida, à posição do México, como se pode verificar na tabela VII:

\section{Tabela VII: Perspectiva sobre a dominância dos Estados Unidos na disciplina por país}

\begin{tabular}{|cccccc} 
& Argentina & Brasil & Chile & Colômbia & México \\
\hline Discordo fortemente & 9,09 & 22,77 & 0 & 5,88 & 4,65 \\
Discordo & 13,64 & 57,43 & 9,09 & 8,82 & 32,56 \\
Não discordo nem concordo & 22,73 & 1,98 & 9,09 & 11,76 & 13,95 \\
Concordo & 50 & 8,91 & 72,73 & 58,82 & 39,53 \\
Concordo fortemente & 4,55 & 8,91 & 9,09 & 14,71 & 9,30 \\
\hline
\end{tabular}

Fonte: Maliniak e al. TRIP 2014 Faculty Survey

Ao se observar a Tabela VII acima, verifica-se que as comunidades da Argentina, Chile e Colômbia consideram as relações internacionais uma disciplina predominantemente estadunidense, com destaque para o Chile $(72,73 \%)$. Já no Brasil, destaca-se a soma dos percentuais, de aproximadamente $80 \%$, que discordam ou discordam fortemente dessa afirmação. Ademais, ressalta-se a posição do México que, embora sua comunidade esteja tão próxima aos Estados Unidos geograficamente, mostra que tal comunidade está dividida quanto à maior ou menor influência dos Estados Unidos nessa disciplina.

Em suma, não há um forte consenso entre as comunidades latino-americanas se a disciplina continua a ter o domínio dos Estados Unidos, da forma preconizada por Stanley Hoffman em 1977. As comunidades tendem a se dividir, onde, por um lado, Argentina, Chile e Colômbia reconhecem de maneira mais acentuada a predominância estadunidense, e, por outro lado, a comunidade brasileira e, 
em sequência, a mexicana parecem tender à discordância e resistência quanto à predominância inconteste dos Estados Unidos na área.

Porém, ao se analisar mais resultados do survey TRIP 2014, ainda relacionados à influência estadunidense na disciplina, torna-se possível constatar um maior consenso entre as comunidades latino-americanas. Isso é comprovado pelos resultados ao questionamento quanto à realização de um doutorado nos Estados Unidos e as possíveis maiores chances de sucesso acadêmico no futuro. Os Estados Unidos detêm os principais centros de excelência em docência e pesquisa do mundo e, para a maioria dos pesquisadores da América Latina, um estudante que tenha cursado seu doutorado ou parte dele nos Estados Unidos tem mais chances de ingressar na carreira acadêmica do que um estudante que tenha estudado apenas em seu país, como se pode observar na Tabela VIII a seguir:

Tabela VIII: Maiores chances de sucesso na carreira futura para quem cursa seu PhD nos Estados Unidos, por país

\begin{tabular}{|rrrrrrrrrr|}
\hline \multicolumn{2}{|c}{ Argentina } & \multicolumn{2}{c}{ Brasil } & \multicolumn{2}{c}{ Chile } & \multicolumn{2}{c|}{ Colômbia } & \multicolumn{2}{c|}{ México } \\
\hline Sim & 52,3 & Sim & 49,7 & Sim & 83,3 & Sim & 79,7 & Sim & 59,6 \\
Não & 31,8 & Não & 38,2 & Não & 5,6 & Não & 13,6 & Não & 31,9 \\
\hline
\end{tabular}

Fonte: Maliniak et al. TRIP 2014 Faculty Survey.

Assim, observa-se que, nos cinco países, a maioria acredita que quem realizou seu doutorado ou parte dele nos Estados Unidos terá mais chances de sucesso futuro, havendo, portanto, uma alta expectativa do valor acadêmico agregado à formação intelectual do estudante, ao passar uma temporada de estudos nos Estados Unidos cursando seu PhD. Entretanto, nota-se que há uma notável diferença em termos de equilíbrio percentual entre os acadêmicos da Argentina, Brasil e México, por um lado, e do Chile e da Colômbia, por outro.

Na Argentina, Brasil e México, embora haja uma maioria que acredita em um aumento do valor acadêmico a partir da realização de um PhD nos EUA, há também uma significativa parcela que não acredita nessa afirmação, ou seja, que entende que não necessariamente o jovem que se doutorou nos Estados Unidos irá ingressar no mercado de trabalho mais facilmente. Já para os últimos, Chile e Colômbia, a grande maioria entende ser um ganho, em termos de vantagem comparativa, obter o PhD nos EUA. 
Vale também observar se há convergência ou não quanto às escolhas feitas para os principais programas de doutorado no mundo, para aqueles que desejam seguir a carreira acadêmica. Os dados apontados na tabela IX a seguir evidenciam que parece haver uma maior convergência quanto aos principais programas de doutorado na área de RI estarem nos EUA, embora alguns programas de doutorado da Inglaterra também se destaquem na percepção dos acadêmicos latino-americanos.

Tabela IX: Principais Programas de Doutorado para uma carreira acadêmica

\begin{tabular}{|c|c|c|c|c|c|c|c|c|c|}
\hline \multicolumn{2}{|c|}{ Argentina } & \multicolumn{2}{|l|}{ Brasil } & \multicolumn{2}{|l|}{ Chile } & \multicolumn{2}{|c|}{ Colômbia } & \multicolumn{2}{|c|}{ México } \\
\hline $\begin{array}{c}\text { Harvard } \\
\text { University }\end{array}$ & 65,0 & $\begin{array}{c}\text { Harvard } \\
\text { University }\end{array}$ & 62,0 & $\begin{array}{c}\text { Harvard } \\
\text { University }\end{array}$ & 62,0 & $\begin{array}{c}\text { Harvard } \\
\text { University }\end{array}$ & 76,0 & $\begin{array}{c}\text { Harvard } \\
\text { University }\end{array}$ & 69,1 \\
\hline $\begin{array}{l}\text { Columbia } \\
\text { University }\end{array}$ & 50,0 & $\begin{array}{l}\text { University } \\
\text { of Oxford }\end{array}$ & 46,3 & $\begin{array}{l}\text { University } \\
\text { of Oxford }\end{array}$ & 46,3 & $\begin{array}{c}\text { London } \\
\text { School of } \\
\text { Economics } \\
\text { and Political } \\
\text { Science }\end{array}$ & 52,0 & $\begin{array}{l}\text { Columbia } \\
\text { University }\end{array}$ & 47,3 \\
\hline $\begin{array}{l}\text { Princenton } \\
\text { University }\end{array}$ & 45,0 & $\begin{array}{c}\text { London } \\
\text { School of } \\
\text { Economics } \\
\text { and Political } \\
\text { Science }\end{array}$ & 42,6 & $\begin{array}{c}\text { London } \\
\text { School of } \\
\text { Economics } \\
\text { and Political } \\
\text { Science }\end{array}$ & 42,6 & $\begin{array}{l}\text { University } \\
\text { of Oxford }\end{array}$ & 44,0 & $\begin{array}{c}\text { Yale } \\
\text { University }\end{array}$ & 40,0 \\
\hline London & & & & & & & & & \\
\hline $\begin{array}{l}\text { School of } \\
\text { Economics } \\
\text { and Political } \\
\text { Science }\end{array}$ & 35,0 & $\begin{array}{l}\text { University } \\
\text { of } \\
\text { Cambrigde }\end{array}$ & 35,2 & $\begin{array}{l}\text { University } \\
\text { of } \\
\text { Cambrigde }\end{array}$ & 35,2 & $\begin{array}{l}\text { Stanford } \\
\text { University }\end{array}$ & 40,0 & $\begin{array}{l}\text { University } \\
\text { of Oxford }\end{array}$ & 32,7 \\
\hline $\begin{array}{c}\text { Yale } \\
\text { University }\end{array}$ & 25,0 & $\begin{array}{l}\text { Princenton } \\
\text { University }\end{array}$ & 34,3 & $\begin{array}{l}\text { Princenton } \\
\text { University }\end{array}$ & 34,3 & $\begin{array}{c}\text { Yale } \\
\text { University }\end{array}$ & 32,0 & $\begin{array}{l}\text { Princenton } \\
\text { University }\end{array}$ & 30,9 \\
\hline
\end{tabular}

Fonte: Maliniak e al. TRIP 2014 Faculty Survey.

Os resultados do survey apontam que, para todas as cinco comunidades, a escolha por Harvard foi unânime, com média de $70 \%$. Na sequência, presentes em quatro países, estão London School, Princeton e Oxford. Tais escolhas refletem uma sintonia entre os acadêmicos da região quanto ao que consideram serem os melhores programas para formação acadêmica no âmbito do doutorado, bem como 
os dados apontam para uma predominância de programas norte-americanos e, em menor medida, os programas ingleses. Talvez seja nesse item, o da valoração de programas de excelência em PhD, que a influência estadunidense (e, em menor medida, inglesa) seja mais evidente e compartilhada entre os acadêmicos latino-americanos.

A predominância dos Estados Unidos também é revelada pelos dados quanto aos autores mais influentes das relações internacionais. E, da mesma forma, as comunidades de RI da região também tendem a ter visões parecidas nesse aspecto, como se pode observar na tabela X.

\section{Tabela X: Autores mais influentes da disciplina de relações internacionais, por país}

\begin{tabular}{|c|c|c|c|c|c|c|c|c|c|}
\hline \multicolumn{2}{|c|}{ Argentina } & \multicolumn{2}{|c|}{ Brasil } & \multicolumn{2}{|l|}{ Chile } & \multicolumn{2}{|c|}{ Colômbia } & \multicolumn{2}{|c|}{ México } \\
\hline $\begin{array}{l}\text { Alexander } \\
\text { Wendt }\end{array}$ & 45,7 & $\begin{array}{l}\text { Alexander } \\
\text { Wendt }\end{array}$ & 35,3 & $\begin{array}{l}\text { Alexander } \\
\text { Wendt }\end{array}$ & 46,7 & $\begin{array}{l}\text { Alexander } \\
\text { Wendt }\end{array}$ & 48,1 & $\begin{array}{l}\text { Robert O. } \\
\text { Keohane }\end{array}$ & 28,4 \\
\hline $\begin{array}{l}\text { Robert O. } \\
\text { Keohane }\end{array}$ & 25,7 & $\begin{array}{l}\text { Joseph S. } \\
\text { Nye Jr }\end{array}$ & 32,4 & $\begin{array}{l}\text { Joseph S. } \\
\text { Nye Jr }\end{array}$ & 40,0 & $\begin{array}{l}\text { Joseph S. } \\
\text { Nye Jr }\end{array}$ & 30,8 & $\begin{array}{l}\text { Alexander } \\
\text { Wendt }\end{array}$ & 18,9 \\
\hline $\begin{array}{l}\text { Barry } \\
\text { Buzan }\end{array}$ & 25,7 & $\begin{array}{l}\text { Robert O. } \\
\text { Keohane }\end{array}$ & 30,0 & $\begin{array}{l}\text { Robert O. } \\
\text { Keohane }\end{array}$ & 33,3 & $\begin{array}{l}\text { Kenneth } \\
\text { Waltz }\end{array}$ & 25,0 & $\begin{array}{l}\text { Joseph S. } \\
\text { Nye Jr }\end{array}$ & 17,6 \\
\hline $\begin{array}{l}\text { Robert W. } \\
\text { Cox }\end{array}$ & 20,0 & $\begin{array}{l}\text { Barry } \\
\text { Buzan }\end{array}$ & 27,1 & $\begin{array}{l}\text { Francis } \\
\text { Fukuyama }\end{array}$ & 20,0 & $\begin{array}{l}\text { Barry } \\
\text { Buzan }\end{array}$ & 23,1 & $\begin{array}{l}\text { Kenneth } \\
\text { Waltz }\end{array}$ & 13,5 \\
\hline $\begin{array}{l}\text { Joseph S. } \\
\text { Nye Jr. }\end{array}$ & 20,0 & $\begin{array}{l}\text { Kenneth } \\
\text { Waltz }\end{array}$ & 21,2 & $\begin{array}{l}\text { Samuel P. } \\
\text { Huntington }\end{array}$ & 20,0 & $\begin{array}{l}\text { Robert O. } \\
\text { Keohane }\end{array}$ & 23,1 & $\begin{array}{l}\text { Samuel P. } \\
\text { Huntington }\end{array}$ & 10,8 \\
\hline
\end{tabular}

Fonte: Maliniak e al. TRIP 2014 Faculty Survey.

Assim, nas cinco comunidades de RI latino-americanas, autores estadunidenses dominam as listas ou ranking de autores mais influentes na área. No entanto, a Argentina é o país mais diversificado ao incluir dois de origem canadense entre os cinco primeiros de sua lista (Barry Buzan e Robert Cox). Também é notório que todas as cinco comunidades identificam, como autores mais influentes, estadunidenses de perspectivas teóricas tradicionais positivistas (liberais e realistas), porém quase todos, com exceção do México, indicam também um autor construtivista como o autor mais influente na comunidade daquele país (Barry Buzan ou Alexander Wendt). 
Essa predominância estadunidense é também notável quando são listadas as revistas consideradas as mais influentes para a área de RI, o que reforça a percepção sobre o domínio estadunidense na produção científica da área.

\section{Publicações}

Em termos de publicações, é possível também observar uma variação entre os produtos mais valorizados nas instituições de origem dos pesquisadores, pois, em caráter de exemplo, livros de editoras universitárias ou comerciais, artigos em revistas nacionais de alta qualificação ou periódicos com alta pontuação são mais bem classificados do que artigos de revistas internacionais de alto impacto e avaliados por pares. Ademais, existe certo consenso entre os pesquisadores de todos os cinco países em valorar menos publicações tais como posts em blogs, blog de ciência política, ou artigo em jornal de circulação nacional, em magazine ou em relatórios de política.

A pesquisa incluiu também uma pergunta sobre qual o peso que a disciplina deveria atribuir a um artigo publicado em alguns tipos de publicações, quando se trata de definir a posição permanente de um professor na carreira docente, comparadas àquelas publicações, como um artigo em um periódico, que utilize a revisão por pareceristas. As respostas revelam que o livro de uma editora universitária nacional ou estrangeira, ou de uma editora comercial deveria ter mais valor do que o artigo de um periódico revisado por pareceristas.

Coerentemente com os resultados anteriores, os pesquisadores daqueles países não consideram a citação indexada como a melhor maneira de medir o impacto acadêmico de uma determinada publicação. Na Colômbia (45,7\%), México $(51,8 \%)$, Brasil $(33,3 \%)$ e Argentina (58,8\%), os pesquisadores não usam um sistema formal de classificação como o Social Science Citation Index-SSCI, Índice de Citação de Ciências Sociais. Para julgar a qualidade de um determinado periódico, por exemplo, no caso do Chile, a maior parte dos entrevistados (50\%) prefere um processo informal ao SSCI. Apesar disso, os pesquisadores latino-americanos reconhecem que alguns periódicos, sobretudo de origem nos EUA, publicam os artigos com maior influência sobre a forma como a disciplina é definida. 


\section{Tabela XI: Quatro periódicos que publicam artigos com grande influência na disciplina de RI}

\begin{tabular}{|c|c|c|c|c|c|}
\hline Ranking & Colombia & Chile & Mexico & Brazil & Argentina \\
\hline 1. & Foreign Affairs & Foreign Affairs & Foreign Affairs & Foreign Affairs & $\begin{array}{l}\text { International } \\
\text { Organization }\end{array}$ \\
\hline 2. & Foreign Policy & Foreign Policy & $\begin{array}{l}\text { International } \\
\text { Organization }\end{array}$ & $\begin{array}{l}\text { International } \\
\text { Organization }\end{array}$ & $\begin{array}{l}\text { International } \\
\text { Security }\end{array}$ \\
\hline 3. & $\begin{array}{l}\text { International } \\
\text { Organization }\end{array}$ & $\begin{array}{l}\text { International } \\
\text { Studies } \\
\text { Quarterly }\end{array}$ & Foreign Policy & $\begin{array}{l}\text { Revista } \\
\text { Brasileira } \\
\text { de Política } \\
\text { Internacional }\end{array}$ & World Plitics \\
\hline 4. & $\begin{array}{l}\text { American } \\
\text { Journal of } \\
\text { Political Science }\end{array}$ & World Politics & $\begin{array}{l}\text { Le Monde } \\
\text { Diplomatique }\end{array}$ & $\begin{array}{l}\text { International } \\
\text { Security }\end{array}$ & Millennium \\
\hline
\end{tabular}

Quanto aos periódicos de maior influência na área, percebe-se que há, de modo geral, uma consonância quanto às percepções dos acadêmicos latino-americanos. Em primeiro lugar, o periódico International Organization é o único periódico classificado pelos estudiosos latino-americanos dos cinco países dentro do ranking dos quatro mais importantes. Revistas mais focadas em política internacional do que em discussões teóricas, tais como Foreign Affairs, e, em menor proporção, Foreign Policy, são reconhecidas por quatro das cinco comunidades com um lugar privilegiado no ranking, o que poderia estar relacionado ao fato de que a maioria dos pesquisadores latino-americanos consideram que o meio acadêmico e a prática política caminham juntos e deveriam estar vinculados.

O Brasil é o único caso cuja comunidade de RI classifica uma revista nacional (Revista Brasileira de Política Internacional-RBPI) como um dos meios mais influentes na disciplina, algo que nos convida a pensar sobre o desenvolvimento do campo no país e sua inserção nos debates globais (ou, em termos contrários, também de um crescimento de uma atitude paroquial por parte dos pesquisadores brasileiros). A Argentina é o único país onde um periódico que não seja mainstream, como o Millennium, é escolhido como um dos quatro mais influentes da disciplina, o que sugere que abordagens alternativas e críticas são mais valorizadas por estudiosos desse país do que por seus pares no restante da América Latina. 
Há, por fim, também um consenso entre os pesquisadores das cinco comunidades quanto às editoras com a maior influência no campo das relações internacionais. Há duas editoras universitárias que são reconhecidas pelos estudiosos da Colômbia, Brasil, México e Argentina dentro do ranking das quatro mais influentes: Oxford University Press e Cambridge University Press. Editoras comerciais, como Routledge e Palgrave-MacMillan, foram também classificadas em quatro das cinco comunidades como as mais influentes. O México, por sua vez, expressou uma posição distinta, onde pesquisadores mencionaram editoras universitárias como as mais influentes: tais como Cambridge, Columbia, Cornell e Harvard.

\section{Política Internacional}

Um dos resultados importantes do survey de 2011, em países latino-americanos, foi a existência de uma relação entre interesses de pesquisa e percepções da política internacional, bem como entre o lugar que os países ocupam no mundo e suas respetivas políticas externas. O survey do TRIP 2014 revela que houve mudanças que trouxeram novas questões significativas a serem analisadas nessa última seção.

Pesquisadores da Colômbia $(48,4 \%)$, Chile $(40 \%)$ e Brasil $(27,4 \%)$ consideram que a região mais estratégica do mundo para seus respectivos países é a América Latina. Para os argentinos (42,8\%) é a América do Sul e, para os mexicanos $(60,7 \%)$, é a América do Norte. Existe também consenso entre os estudiosos dos cinco países sobre quais regiões são menos importantes em termos estratégicos: Ásia Central, Oceania, Rússia e países da antiga União Soviética, Turquia e África Subsaariana.

Quanto aos desafios ou pressões enfrentadas pelas políticas externas dos países latino-americanos nos próximos 10 anos, as opiniões não são unânimes, como se observa na Tabela XII abaixo. Acadêmicos colombianos e mexicanos concordam em identificar o crime organizado transnacional como um desafio mais importante do que as políticas externas que seus países enfrentam hoje. As comunidades do Chile, Brasil e Argentina identificam a integração regional como a principal preocupação política do momento. Ambas as tendências são explicadas precisamente por problemas históricos e atuais: Colômbia e México compartilham percepções de ameaça não só por causa do tráfico de drogas, mas também pela existência de outros tráficos ilegais, como armas ou pessoas. Da mesma forma, a integração regional é uma questão importante para países como Argentina ou Brasil, que desenvolveram esforços e projetos importantes durante as duas últimas décadas em matéria de integração regional. 


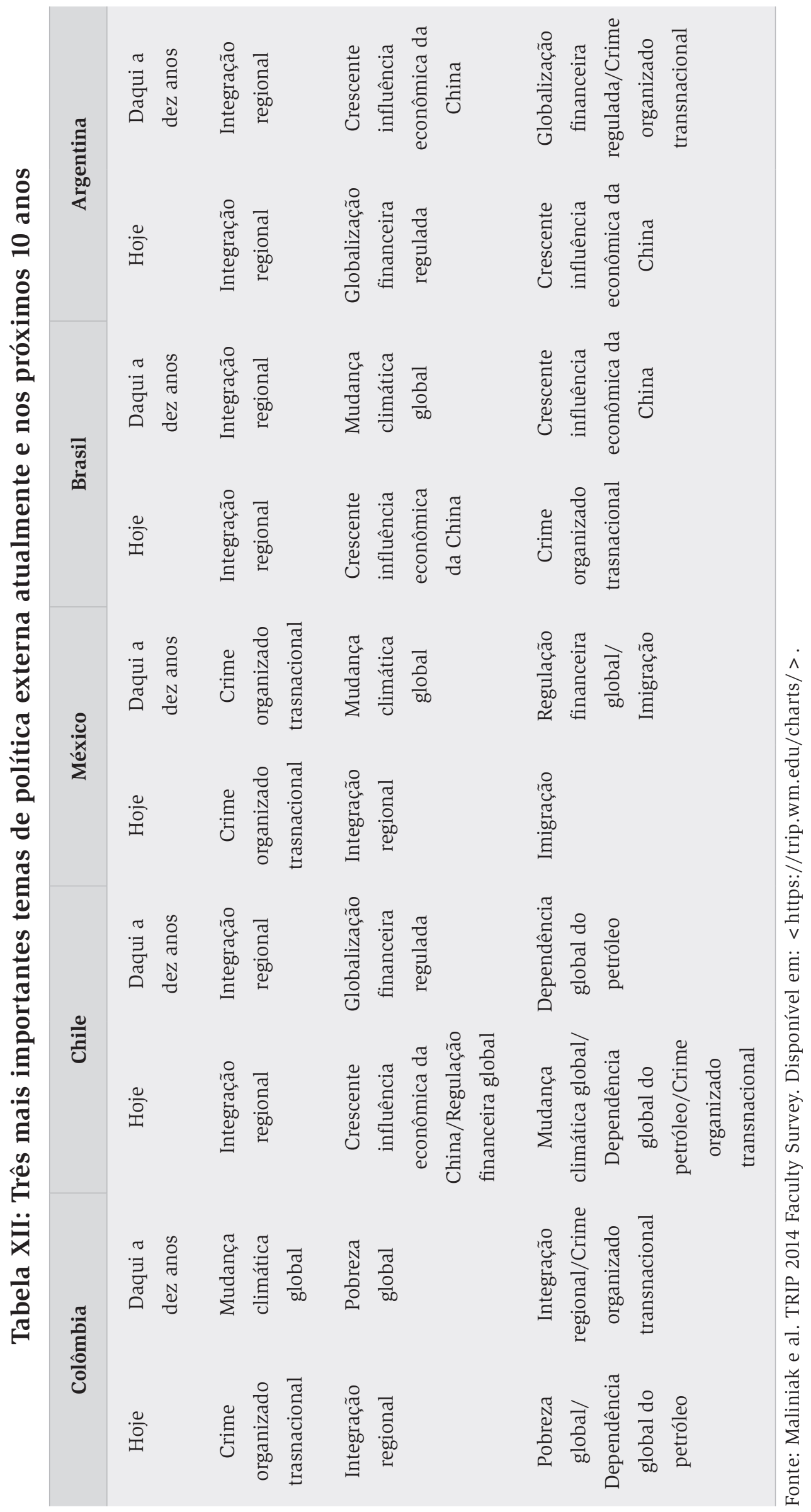


Os tópicos que poderiam ser consideradas questões globais, como a regulação financeira global, a pobreza global ou a crescente influência econômica da China são considerados também como relevantes para as comunidades dos cinco países, com algumas nuances. A influência da China é uma questão que sobressai para os estudiosos chilenos e brasileiros de hoje, e será um tema importante para os argentinos ao longo dos próximos dez anos. Ademais, o tema da regulação financeira global ocupa uma posição importante atualmente na percepção dos chilenos e argentinos e será importante nos próximos dez anos para os mesmos. O Chile e a Colômbia identificam como um problema central a dependência global do petróleo.

Pode-se observar que existe uma congruência entre os problemas identificados na atualidade e os problemas identificados ao longo dos próximos dez anos. Isso poderia significar que os estudiosos latino-americanos percebem os desafios à política externa como um processo razoavelmente estável e/ou que a comunidade reconheça esses problemas como estruturais e, em consequência, capazes de desafiar seus respectivos países mesmo no futuro próximo.

Quanto ao princípio da não intervenção, o survey trouxe alguns questionamentos quanto à postura dos acadêmicos no que diz respeito a intervenções internacionais em situações de conflito ou abusos contra os direitos humanos. É importante notar que as comunidades da Colômbia, Chile e Brasil tendem a apoiar algumas intervenções militares, em contraste com os acadêmicos do México e da Argentina, que parecem acolher mais fortemente o princípio da não intervenção, o qual tem raízes importantes na história da América Latina. Essa mudança sobre a intervenção militar torna-se também interessante porque mais de $54,2 \%$ acredita, por exemplo, que foi uma decisão acertada do ex-presidente dos EUA Barack Obama retirar as tropas norte-americanas do Iraque até o final de 2013 e segmentos importantes das comunidades latino-americanas não têm uma ideia clara de quão determinante foi a ausência de ação e de intervenção, direta e explícita, das tropas dos EUA na Síria para o crescimento do ISIS (Estado Islâmico) durante os últimos anos. Em outras palavras, os dados parecem apontar para a existência de um dilema entre as comunidades latino-americanas de RI: cambiante entre apoiar ou não apoiar as intervenções.

Ainda no que diz respeito a percepções de política internacional e governança global, nota-se que as percepções sobre instituições de governança global não têm sido muito otimistas na região. O survey incluiu duas perguntas sobre tal aspecto, uma sobre a regulação financeira e outra sobre doenças pandêmicas. Os resultados permitem afirmar que somente os pesquisadores chilenos têm 
confiança nas medidas e políticas que certas instituições podem adotar a fim de evitar uma crise financeira semelhante à crise financeira de 2008 ou à propagação de doenças pandêmicas. No caso dos acadêmicos colombianos, mexicanos, argentinos e brasileiros, há uma forte tendência a desconfiar de instituições financeiras internacionais, ao passo que os argentinos são mais otimistas em relação às instituições de saúde.

Nesse sentido, não é surpreendente que a maioria dos pesquisadores considere a ação do Estado como um dos principais meios de política externa para influenciar o comportamento de outro Estado, em detrimento de instituições de governança global. Ferramentas como a extensão ou retirada de assistência econômica, a imposição de sanções comerciais ou concessões comerciais, a promoção ou restrição de investimentos privados são considerados, por parte das comunidades dos cinco países, como poderosos instrumentos para mudar comportamentos de outros Estados, o que, no limite, pode ser evidência de uma percepção de mundo que tende a ser estadocêntrica.

\section{Conclusões}

Esse relatório teve por objetivo principal divulgar amplamente para o meio acadêmico as principais tendências verificadas nos resultados do projeto Teaching Research and International Policy (TRIP) de 2014 para os países da América Latina: Argentina, Brasil, Chile, Colômbia e México. Os resultados trouxeram percepções em torno da comunidade epistêmica latino-americana de Relações Internacionais, quanto ao seu formato, preferências metodológicas, epistemológicas, percepções quanto à dominação norte-americana da área e impressões sobre política internacional.

Um objetivo secundário, mas não menos importante deste relatório, foi possibilitar o levantamento de possíveis reflexões e questionamentos sobre a condução da disciplina de Relações Internacionais, não só no Brasil, mas na América Latina, sobre como é essa comunidade, como pensa e de que forma a área está se consolidando na região. Nesse sentido, possíveis reflexões sobre uma maior ou menor autonomia na área são imprescindíveis para a continuidade de seu processo de adensamento na região.

Tecer considerações finais em um report dessa natureza é uma tarefa das mais desafiadoras, pois qualquer generalização que se faça deve ser balanceada pelo 
fato de se tratar de um survey, cujo alcance foi de cerca de 55,4\% da comunidade identificada naquela ocasião. Entretanto, ao não se levantar considerações gerais acerca do que pôde ser identificado, perde-se a oportunidade de compreender melhor a comunidade latino-americana de Relações Internacionais que está em ascensão.

Portanto, sem perder tal ressalva de vista, a partir dos dados levantados, percebe-se que a comunidade latino-americana está em pleno crescimento, tratando-se de uma comunidade jovem e predominantemente masculina. Quanto às posições ideológicas, há certa inclinação a posições de centro-esquerda, sobretudo no que se refere a questões de âmbito social.

Primeiramente, no campo metodológico, observou-se significativa parcela da comunidade que se debruça no método qualitativo, e posições híbridas quanto à epistemologia e às escolhas paradigmáticas (teóricas). Tal fato é imprescindível para se refletir sobre esse caráter flexível e, em alguma medida, autônomo do pensamento sistemático latino-americano, ao se produzir cientificamente na área de Relações Internacionais, a qual, em maior ou menor medida, não parece se preocupar em se alinhar ao mainstream epistêmico. Entre as comunidades, chamaram atenção o Chile, por demonstrar ser mais alinhado às comunidades mainstream, bem como o México, que, embora tão próximo aos EUA, parece demonstrar posições autônomas e igualmente híbridas quanto ao campo científico de Relações Internacionais.

Em conseguinte, a dominação norte-americana na área pôde ser observada de forma mais evidente nos resultados quanto à percepção dessa dominação e, de forma tangente, quando se observam as reações quanto aos melhores programas de doutorado do mundo, sobre perspectivas de carreira de jovens que cursam seus PhDs ou parte deles nos EUA, ou mesmo quando questionados sobre os journals e autores mais influentes da área. A comunidade brasileira, nesse sentido, foi uma exceção importante, ao demonstrar desconfiança quanto a alguns desses questionamentos, bem como ao acrescentar uma revista brasileira entre as mais importantes da área.

Em terceiro lugar, no que se refere às impressões sobre política internacional, percebeu-se uma convergência entre as comunidades no que diz respeito às questões de política externa que afligem seus respectivos países, e aquelas que seguirão presentes no futuro próximo. Da mesma forma, foi possível perceber uma convergência ao expressarem certa desconfiança quanto à real capacidade de instituições de governança global, seja financeira ou de saúde, para solucionar 
problemas e, dessa forma, tendem a aceitar que os Estados ainda são players centrais da política internacional, e, por meio de suas ações clássicas, como auxílio econômico, bloqueios e sanções, continuam a obter seus resultados políticos esperados do meio internacional.

Por fim, é importante salientar a importância do projeto Teaching Research and International Policy (TRIP), não como o único, mas como um dos instrumentos mais vibrantes existentes hoje para captar a identidade da comunidade epistêmica de qualquer país entre os pesquisados. Dessa forma, encoraja-se a participação efetiva e ampla da comunidade no survey, seja com a finalidade de fomentar reflexões e debates sobre a comunidade epistêmica de relações internacionais, seja para incrementar publicações que se baseiem nos dados do survey no país.

\section{Referências}

HOFFMAN, Stanley. An American Social Science: International Relations. Daedalus. Vol. 106, n. 3, 1977, 41-60.

Maliniak, Daniel, Susan Peterson, Ryan Powers, and Michael J. Tierney. 2014. TRIP 2014 Faculty Survey. Williamsburg, VA: Institute for the Theory and Practice of International Relations. Disponível em: < https://trip.wm.edu/charts/ > . 